Djamila GHRIEB ${ }^{1}$

\title{
THE ARABIC SYLLABLE BETWEEN ANCIENT AND MODERN
}

\section{Istanbul / Türkiye}

\section{p. 23-38}

\section{Article Information}

Article Type: Research Article

This article was checked by

iThenticate No plagiarism

detected

\section{Article History}

Received: 22/04/2021

Accepted: 10/05/2021

published: 01/06/2021

\section{Abstract:}

The Arabic language lived by word of mouth and hearing, conveying the crafts and achievements of its people, and this nature has contributed to purifying the Arabic voices from everything that limits their flow, or stops without interrupting its Syllables in an attractive musical rhythm.

The idea of dividing speech into syllables is a long-standing idea among Arabs. Its source extends, in what we think, to that long phase in which concepts and terms in the passage are cracked.

We want from this study to clarify what came from the Arabic tongue in their books on the Syllable and the exit with Sahih al-Bayan.

Key words: Syllable Tissue, Word, Vocal Unit.

http://dx.doi.org/10.47832/2791-9323.2-2.3

1 (D) Dr. , Badji Mokhtar University, Algeria, ghriebdjamila.2015@gmail.com, https://orcid.org/0000-0002-2431-3939

Copyright ๑ Published by IJEl Journal, wwwijeljournal.com 


\section{المقطع العربي بين القديم والحديث}

\section{2}

\section{الملخص}

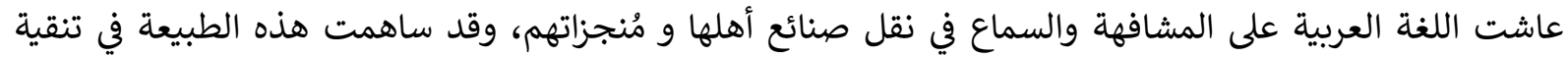

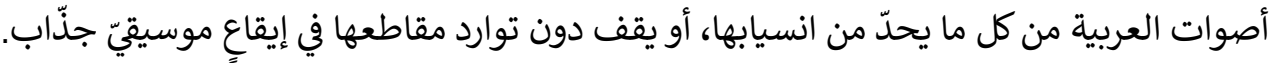

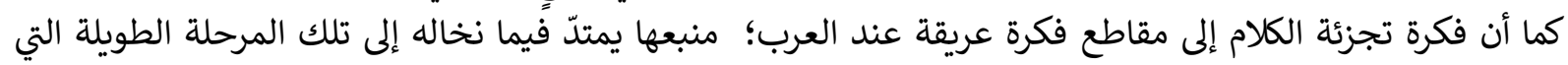

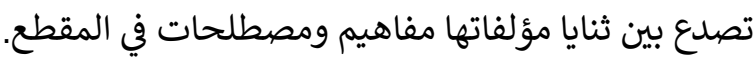

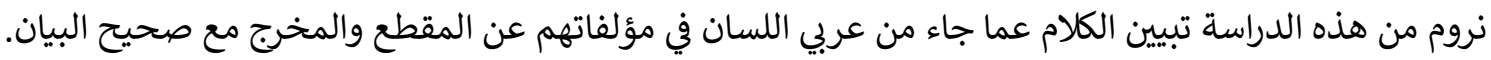
الكلمات المفتاحية: النسيج المقطعي، الكلمة، الوحدة الصوتية الرئية

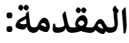

تناول كثير من الدارسين موضوع المقطع بالدرس والتحليل، رغم تضارب آراء العلماء بوصفه ظاهرة مقتصرة على اللغات

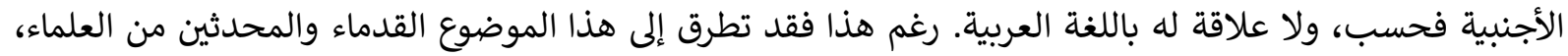

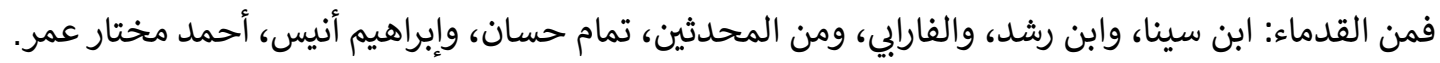

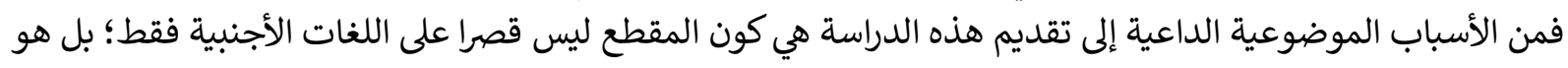

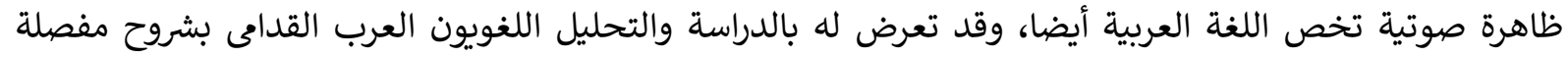
وعلمية.

أي المقاطع أكثر شيوعا في النسيج العام للوحدة المعجمية ؟ والغاية من وراء هذا البحث هو تعريف القئ القارئ الكريم، بالنسيج العام للمقطع العربي وخصائصه، وما يميزه عن غيره من المقاطع اللغوية للغات أخرى.

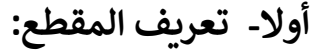

لم يتفق علماء الأصوات على تعريف واحد للمقطع "Syllabe*" ويرجع ذلك لاختلاف الرؤى حول الوظيفة الفيزيائية

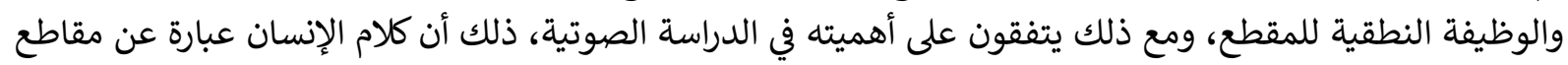

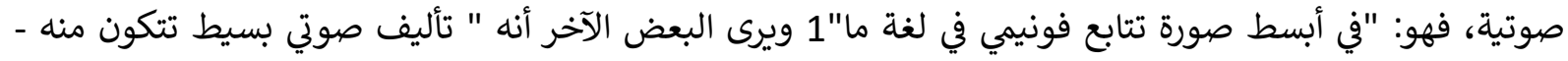

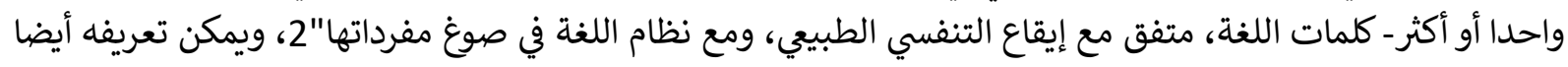

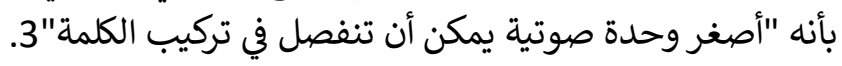

\section{ثانيا- الاتجاهات الرئيسية في تعريف المقطع: يمكن حصر هذه التعريفات في اتجاهين رئيسين هما:

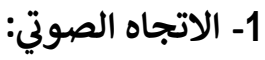

استقر أتباع هذا الاتجاه على أن الأصوات تميل في تجمعها تبعا لما تتميز به من جهر أو وضوح سمعي، وأن هذا الجانب له دور مهم في تكوين البنى المقطعية، فقد عرّفه:

ودم، ، و جامعة باجي مختار-عنابة، الجزائر ، gmail.com 


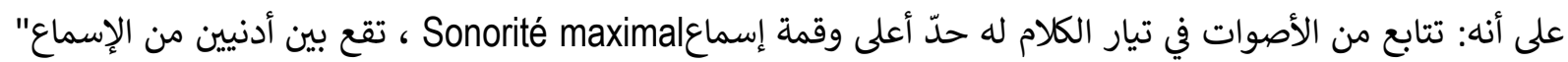

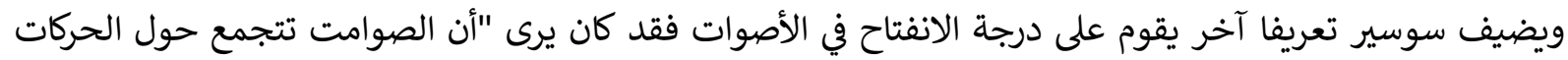

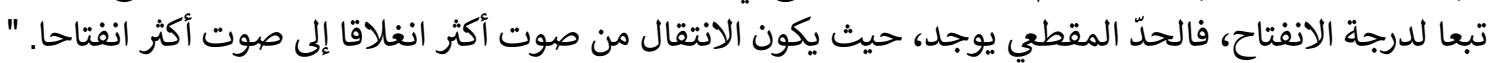
Si dans une chaine de sons on passe d'une implosion à une explosion, on obtient un effet particulier qui est l'ndice de la frontière de syllabe.

La frontières syllabiques peut être, dans certains cas, placées en deux points différents d'une série de phonèmes, suivant qu'in passe plus ou moins vite de l'implosion à l'explosion

$$
\text { ولم يذهب عن سوسير عالم آخر في الصوتيات: }
$$

ب- جسبرسن(1943 - 1860)

ويقول: "الوحدات الصوتية، تريط في تجمعها بالوحدة الأندى في السمع وأصفاها"

H - R Robins- ج

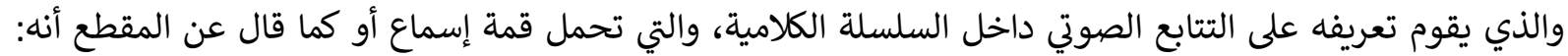

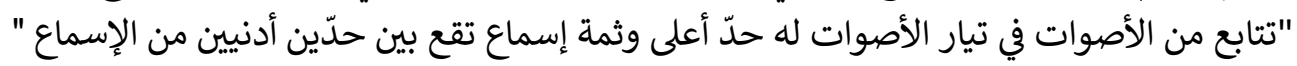

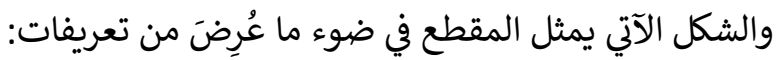

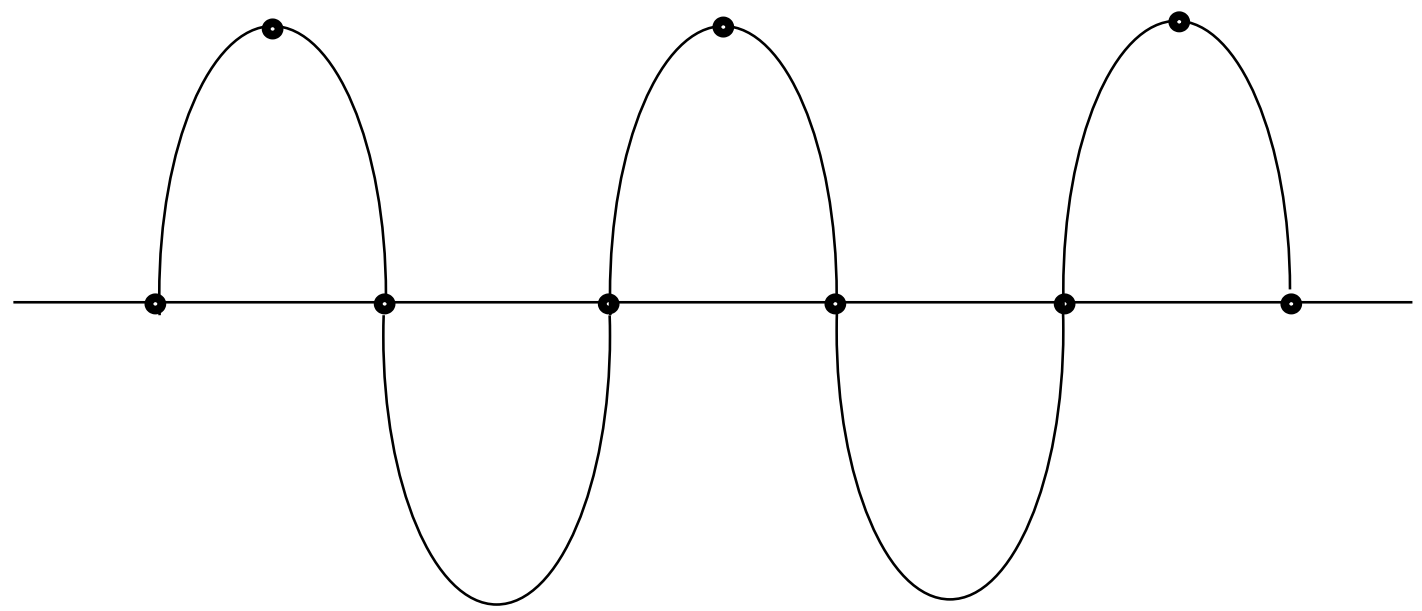

حيث ترمز النقاط ( 1، 3، 5 ) إلى أعلى قمم الإسماع و (2، 4) إلى أدناها فالخط (أ- ب) يمثل الوسط الذي ينتقل

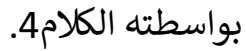
يرى أصحاب هذا الاتجاه أن: "المقطع أصغر كتلة في تركيب المفردة"5، كما أنه "وحدة ذات صفات صفات وخصائص متميزة

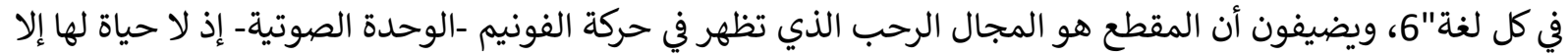

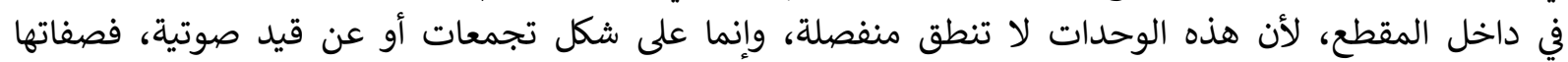

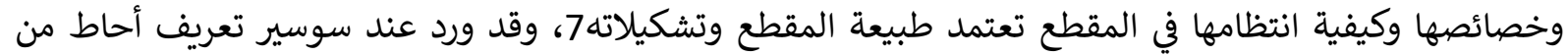

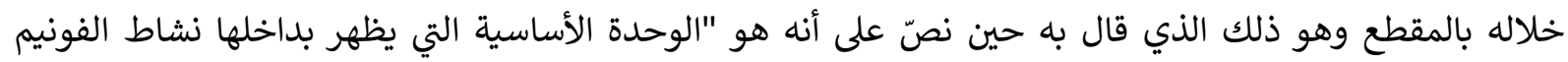

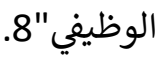

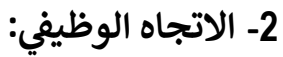

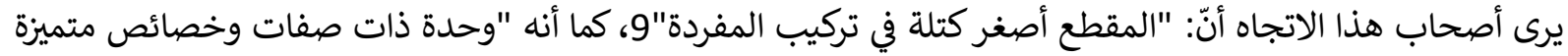

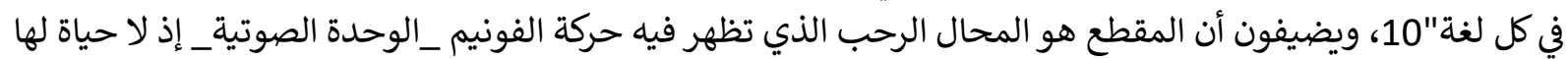

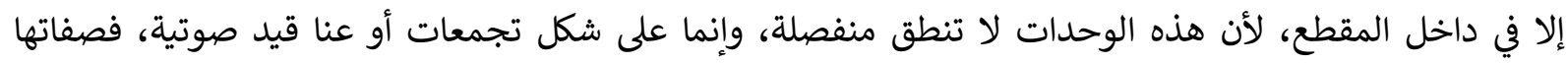

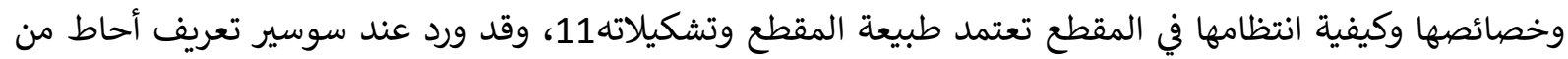


International Journal of Education and Language Studies

خلاله بالمقطع وهو ذلك الذي قال به حين نصّ على أنه هو "الوحدة الأساسية التي يظهر بداخلها نشاط الفونيم الوظيفي"12.

ثالثا- إسهامات القدامى في الدراسة المقطعية: - الم

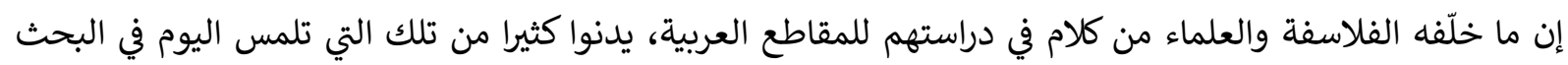

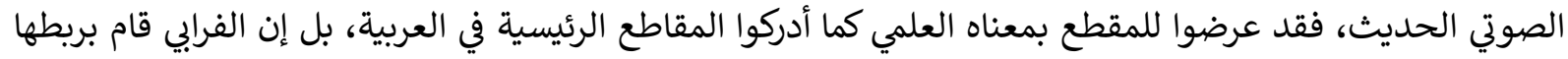
ومعطيات الدرس العروضي عند قدامى النحاة واللغويين:

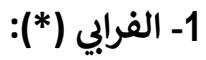

المقطع عده هو حصيلة إقتران حرف غير مصوّت -صامت- بحرف مصوّت -صائت- فيقول: "المقطع مجموع حرف

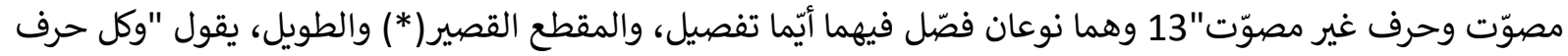

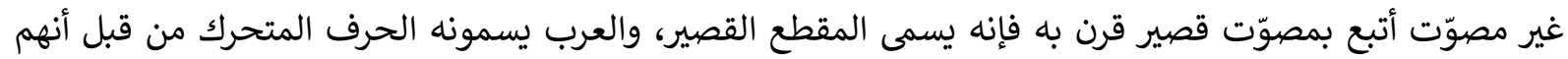

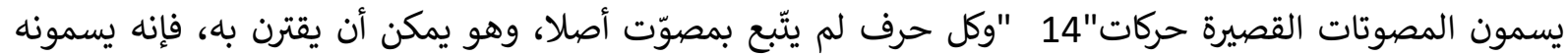

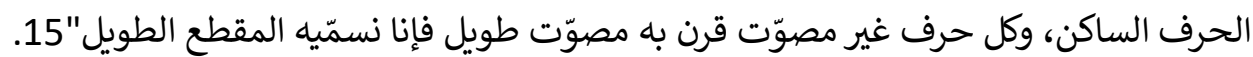

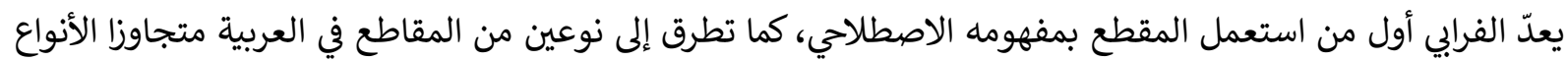

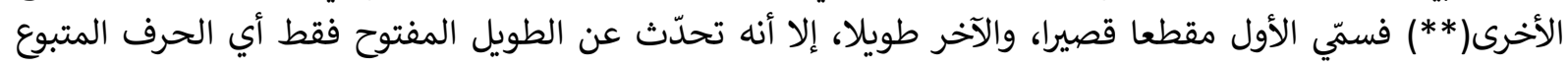

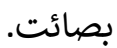

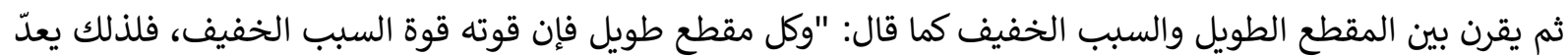

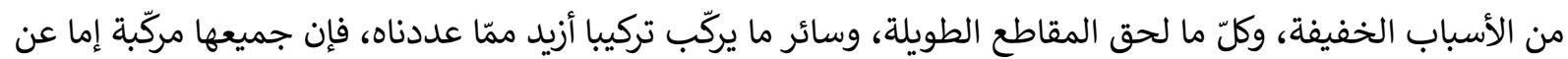

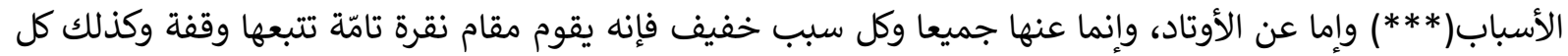
مقطع طويل"16

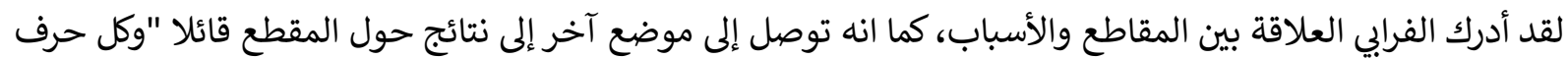

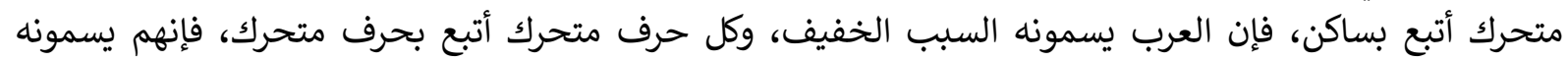

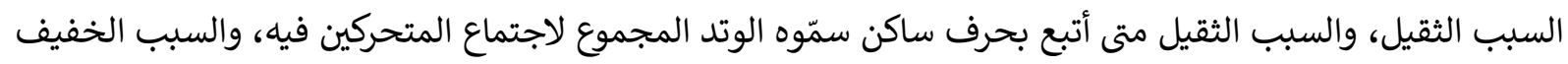

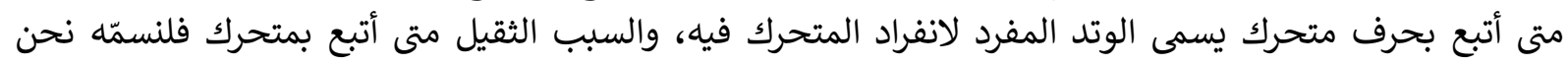
السبب المتوالي، لتوالي المتحركات الثلاثة فيه" المتئ المفرد لانفراد

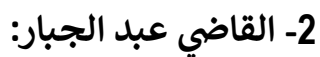

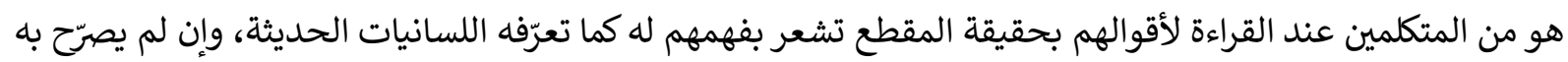

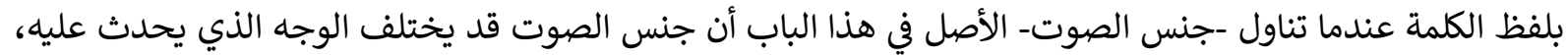

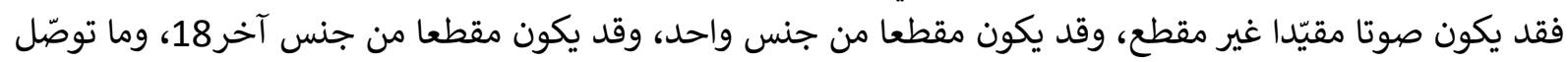

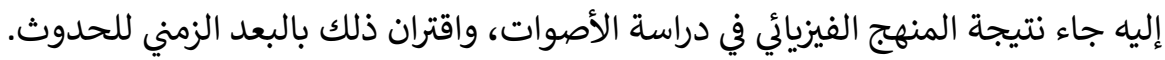

3-) ابن سيناء)

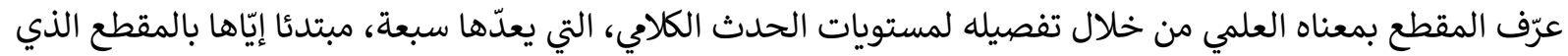

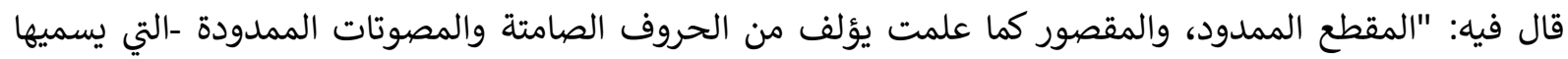

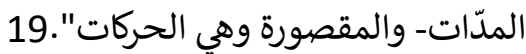




\section{4- ابن رشد)*):}

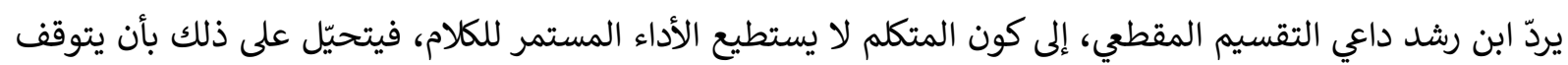

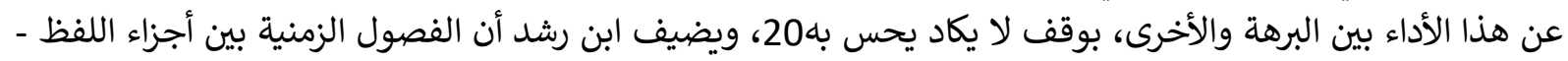

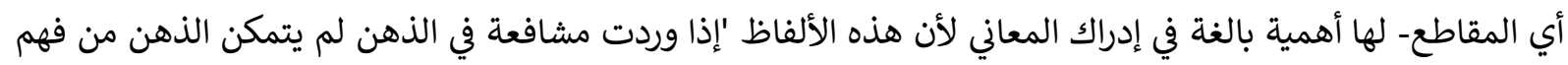

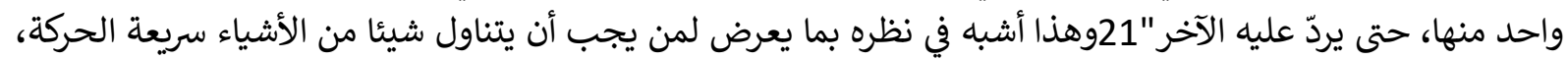

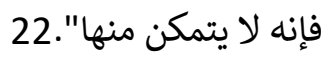

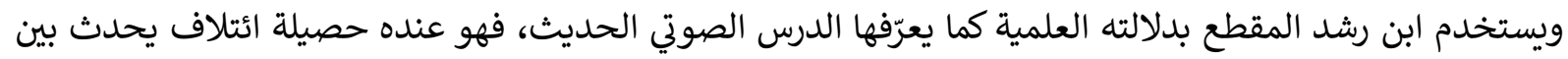

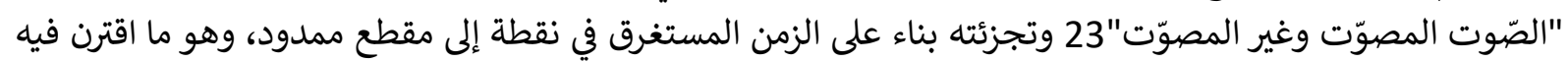

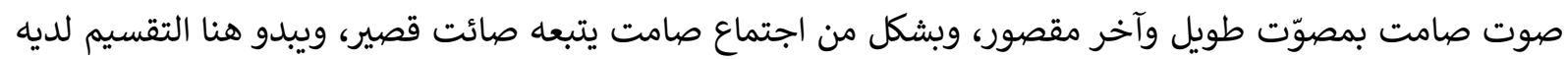

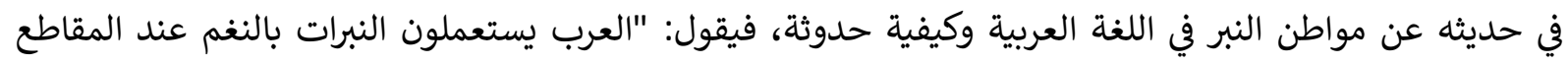

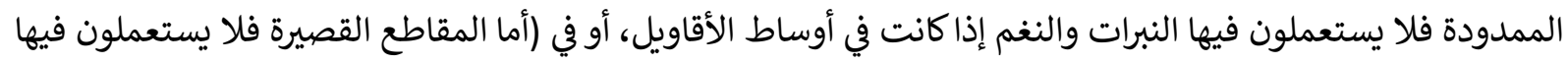

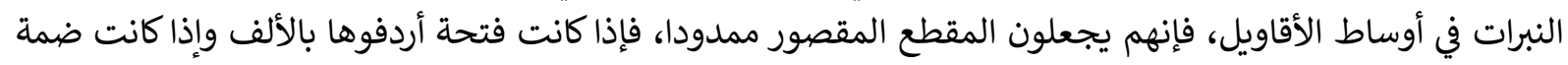

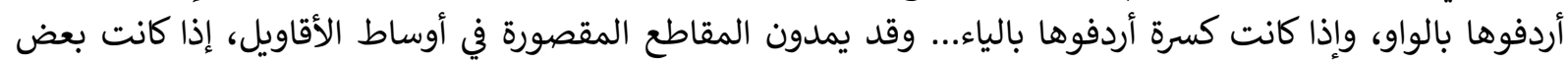

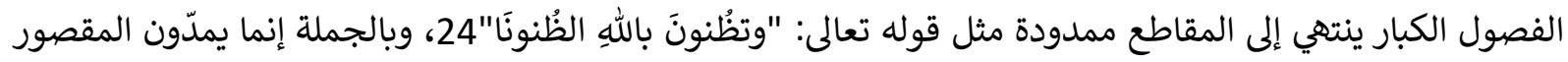

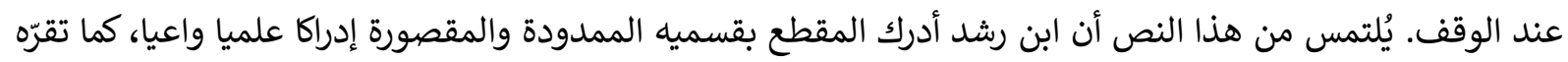

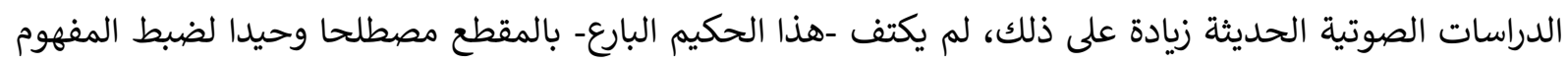

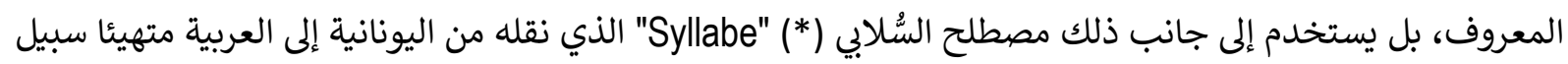

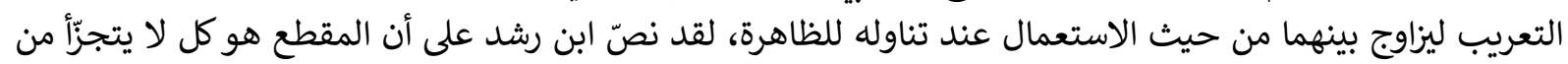

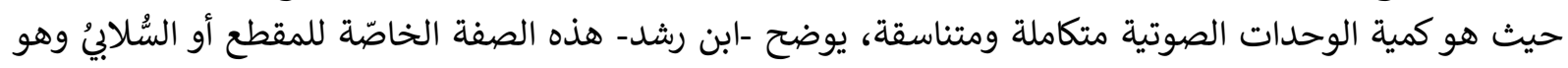

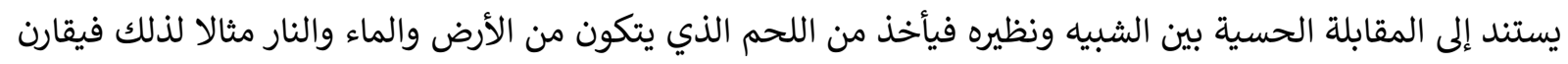

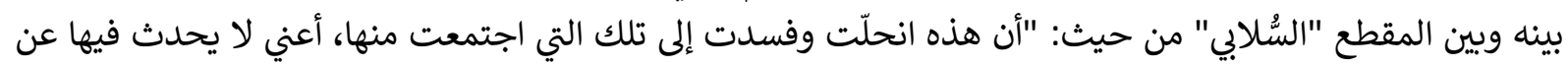

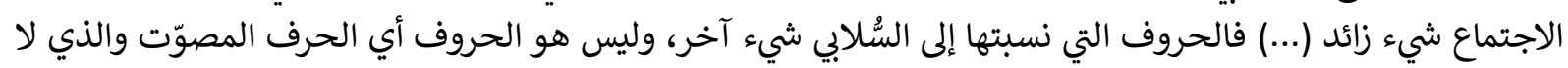

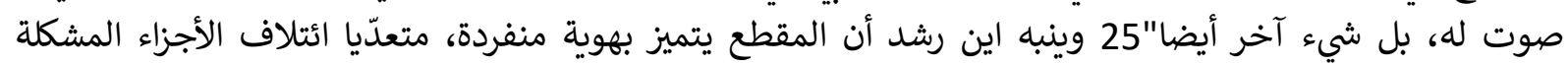

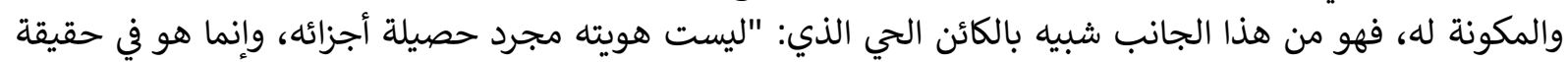

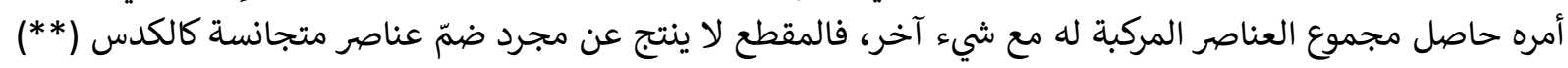

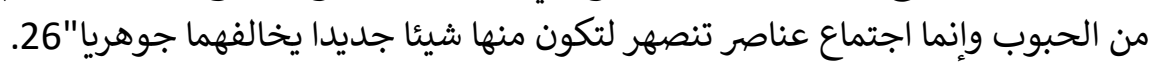

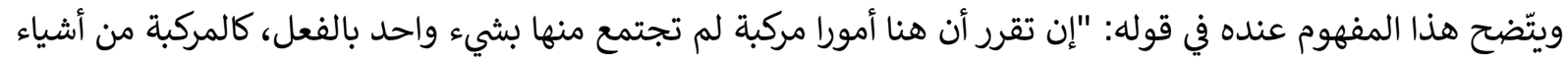

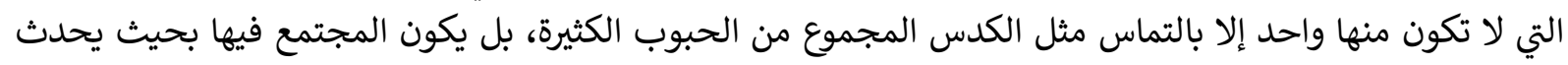

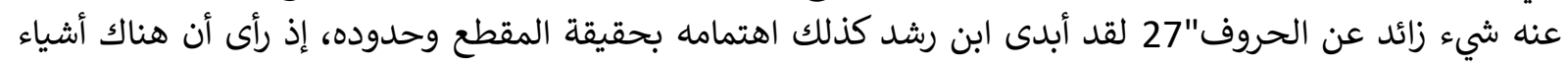

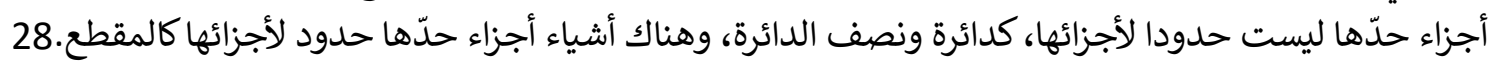

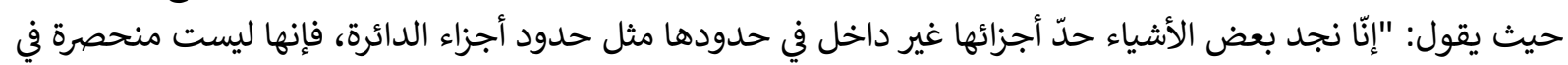

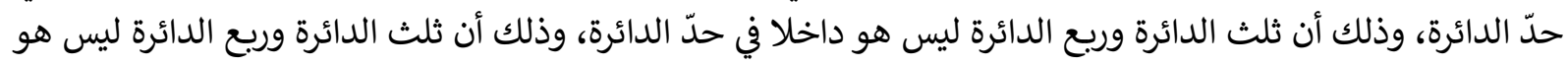

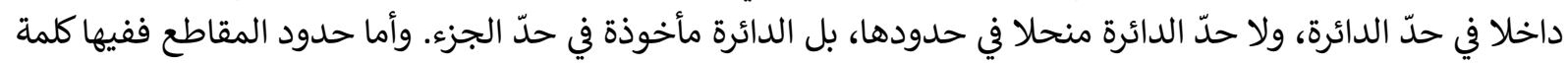

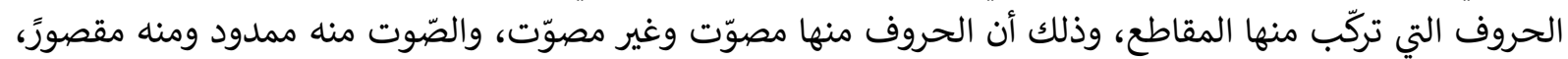

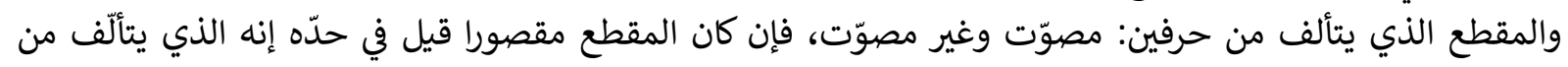

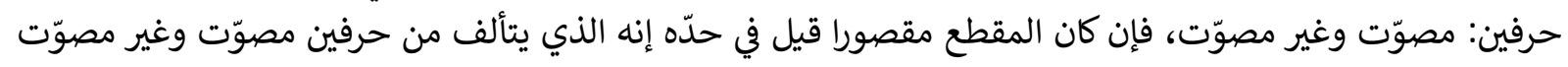

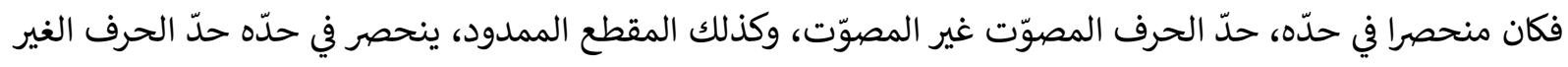

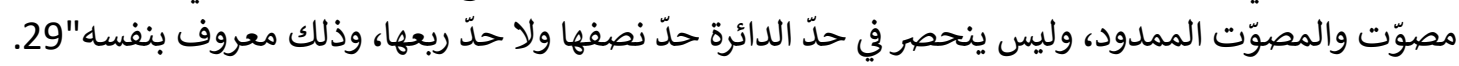




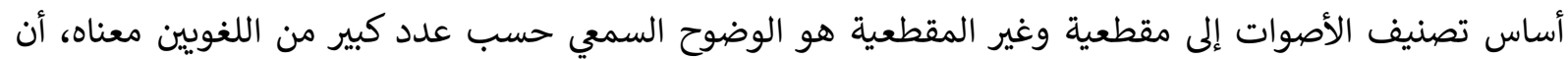

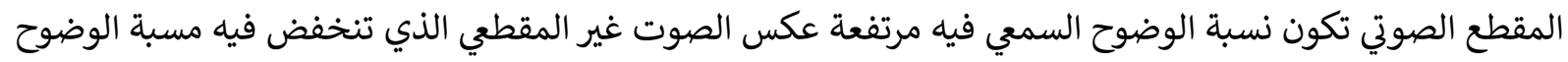

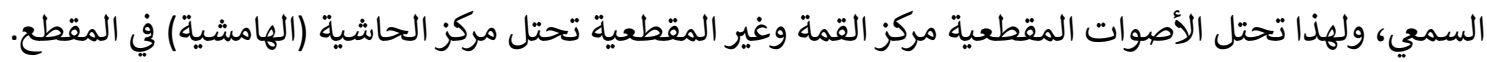

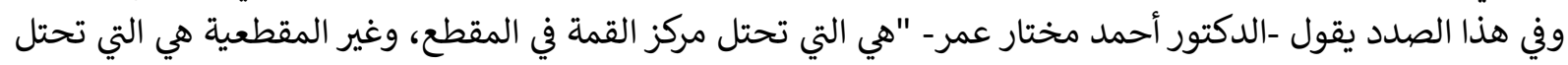
مركز الحاشية أو الهامش في في المقطع" الدكتول

تقسم المقاطع من الناحية المقطعية وعددها ثلاثة أنواع(*).

أ- نوع لا يقع إلا جوهر أو قمة في المقطع: لهذا فهو مقطي Syllabé دائما ولا يدخل في هذا النوع إلا العلل

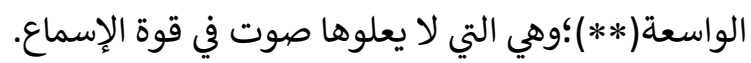
ب- نوع لا يقع إلا هامشا في المقطع:

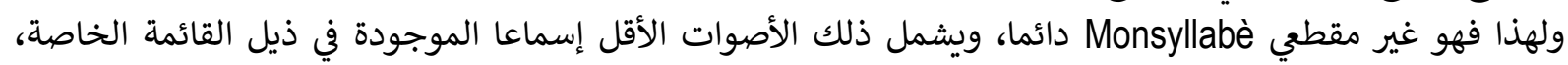

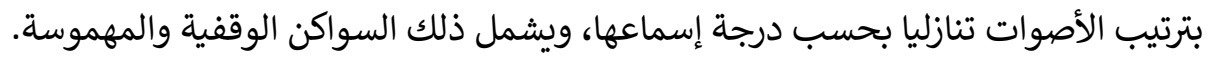
ج- نوع صالح للحالتين: بحسب درجة 'سماع مصاحباته، وهو النوع الوسط بين النوعين السابقين والأكثر من ناحية العدد وليس أكثر نسبة للوقوع. ومن أمثلة ذلك (أ) بين ساكنين أقل إسماعا في الكلمة التشكيلية VIK ولهذا فهي تمثل قمة المقطع و وقع ال (أ) في جوار

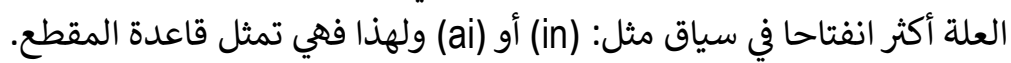

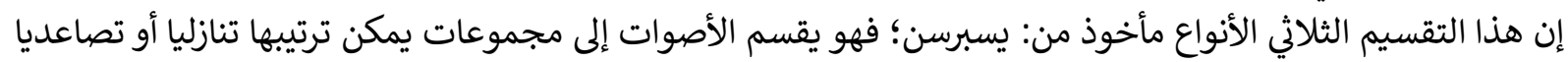

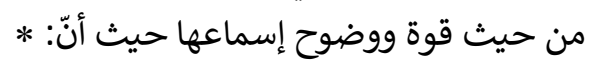

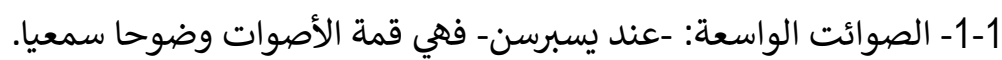

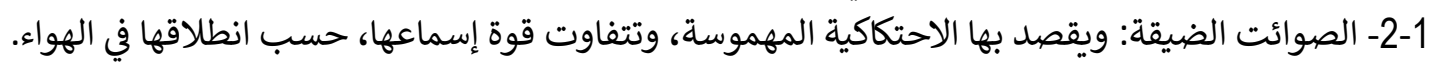

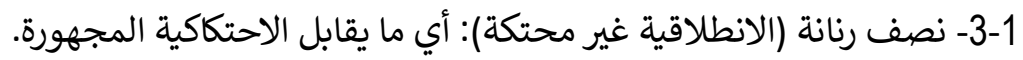

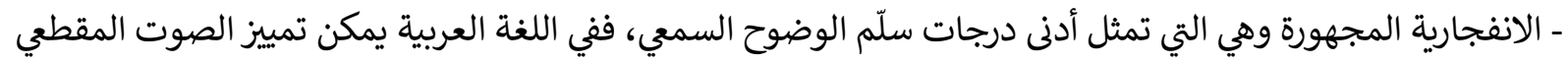
وغير المقطي بـ

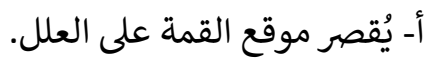
ب- يقصر موقع الهامش على السواكن.

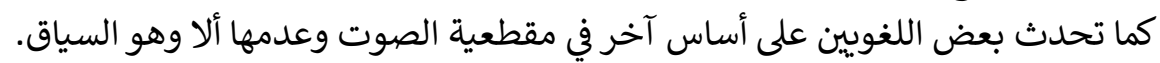

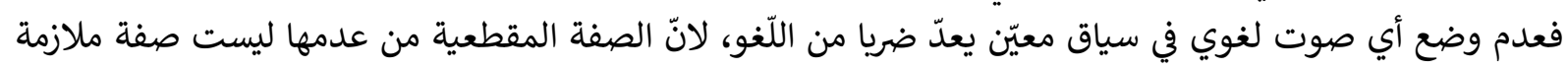

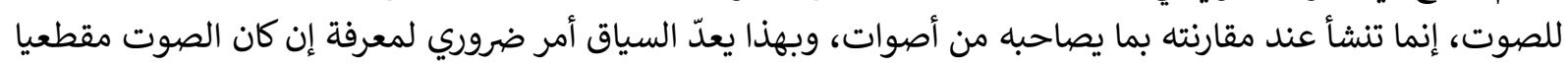

\section{2- 2 - 2 التركيب الفيزيائي للمقطع:}

المقطع كما يوصف بناؤه قطاع من سلسلة التيار الكلامي يشتمل على صوت مقطعي أعظم يحيط به قطاعان ضعيفان من ناحية الصوتية. 
وهذا ما حاول إبرازه الدكتور -عبد القادر عبد الجليل-31 بمخطط مثل فيه التناوب الفيزيائي لأعلى قمم الإسماع وأدناها

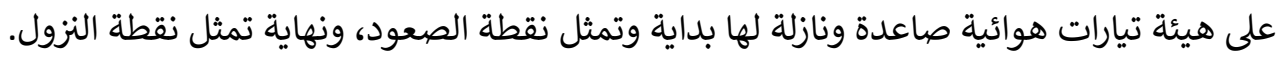

\section{3- التركيب الصوتي للمقطع:}

من خلال النقاط 4-1 في التركيب الفيزيائي يمكن رسم حدود المقطع:

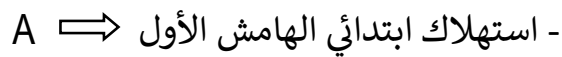

$$
\begin{aligned}
& \text { C القمة (نواة المقطع) - }
\end{aligned}
$$

- ذيل المقطع الهامش الثاني -

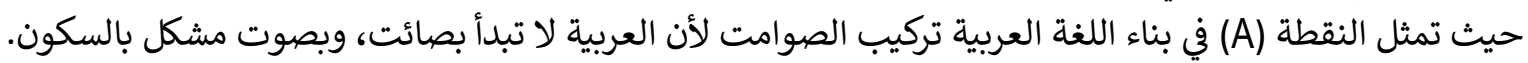

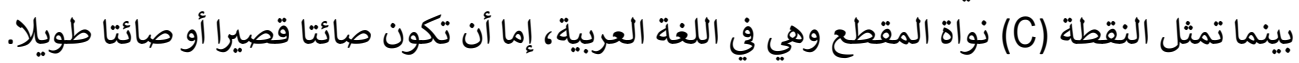

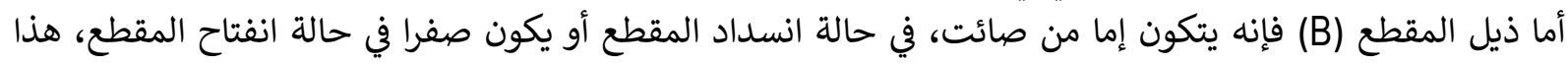
المخطط يبين التركيبة التي يتكون منها هذا المقطع العربي مرتكزا في تصنيفه على إنى الإيضاح السمبي.

\section{4- - 2 - التركيب الفيزيولوجي للمقطع:}

يتكون المقطع من ثلاث درجات.32

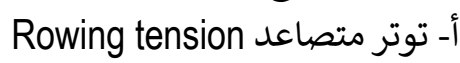
ب- نقطة الذروة في التوتر.

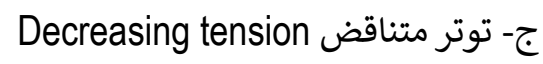
ومثل هذه العناصر الثلاث (المكونات) في مخطط.

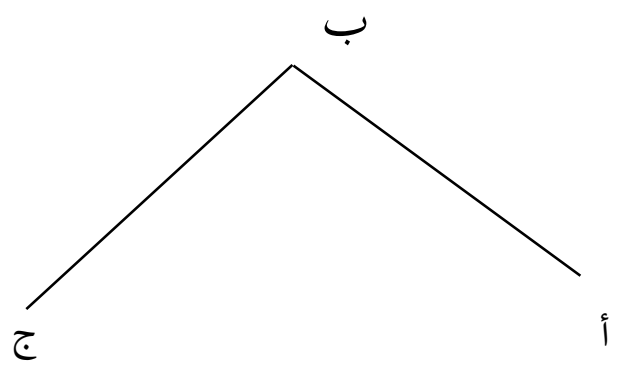

$$
\begin{aligned}
& \text { الخط أ - ب يمثل ارتفاع نقطة التوتر في المقطع } \\
& \text { الخط ب - ج يمثل انخفاض التوتر } \\
& \text { النقطة ب: تمثل نقطة الذروة في المقطع. }
\end{aligned}
$$

أنواع الأنسجة المقطعية:

تتكون اللغة العربية من عدّة تراكيب، وكل تركيب يتكون من وحدات معجمية، وهذه الوحدات عبارة عن وحدات

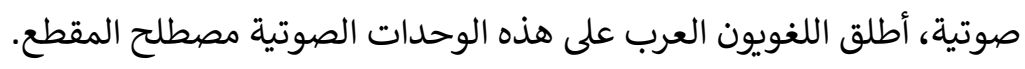

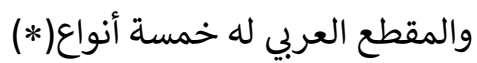

$$
\text { - } \text { - }
$$


International Journal of Education and Language Studies

\section{وتنقسم الأنواع إلى مقاطع أساسية وأخرى ثانوية.}

أ- المقاطع الأساسية: لأنها توجد في أي موضع في الوحدة المعجمية دون التقيّد بأيّ شروط وهي:

(1) النوع الأول: صامت + صائت قصير مثل كَتَبَّ.

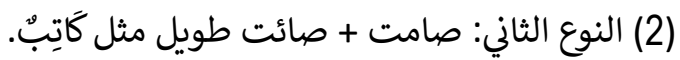

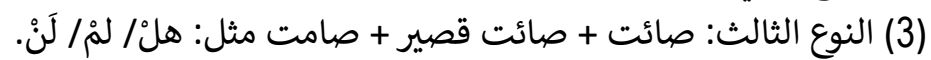

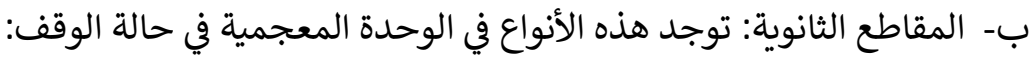

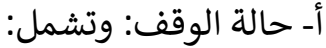

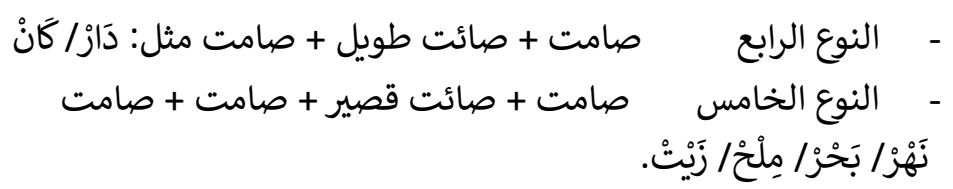

خامسا- المعايير التي تبنى عليها الأنسجة المقطعية:

1- من حيث موضع الصامت: نجد فيه ثلاثة انواع 1-1-1- متحرك "المفتوح" يشمل النوع الأول والثاني 1-2-1- الساكن "المغلق" يشمل النوع الثالث والرابع

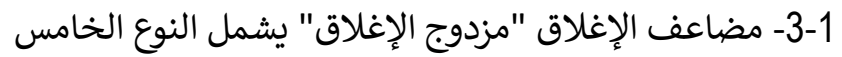

2- من حيث الطول والقصر: يوجد فيه رأيان: - الرأي الأول: بحسب نوع الطول والقهر: يوجئ فيه رأيان أو طويل.

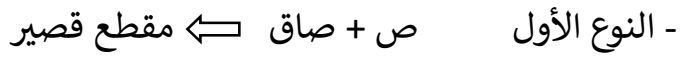

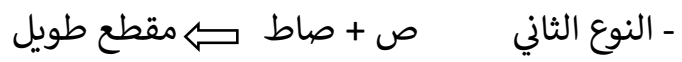

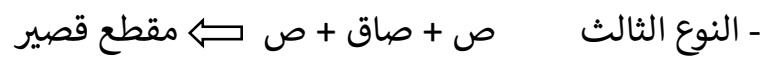

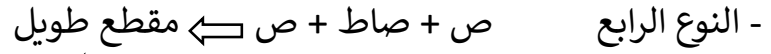

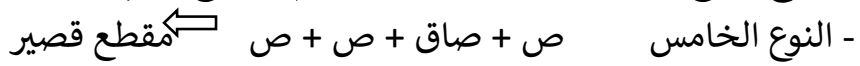
- الري الثاني: بحسب كمية الوحدات الصوتية:

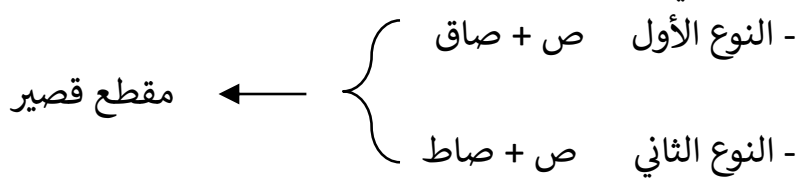
- النوع الثالث

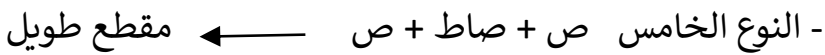

\footnotetext{
وقد وصف العلماء المقطع على أساسين "التسمية"
} 


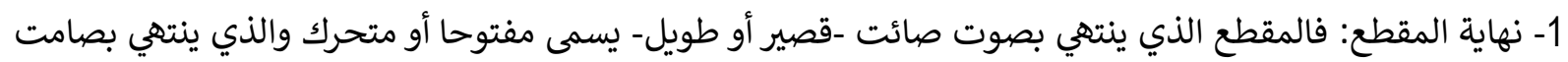

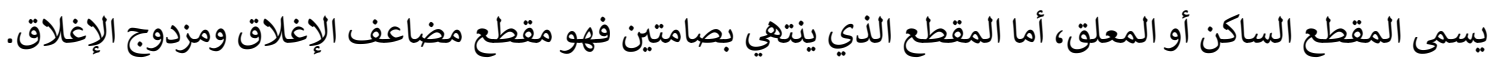

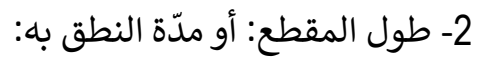

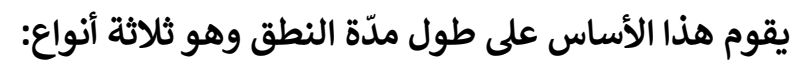

أ- القصير: وهو المقطع الذي يتكون من صوتين.

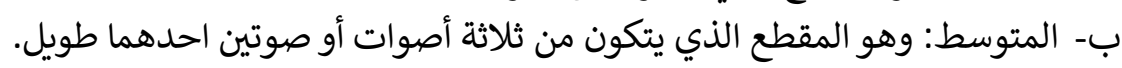

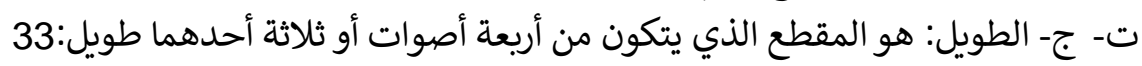

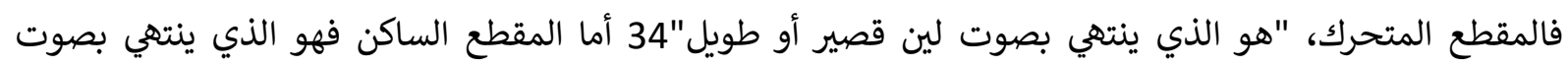

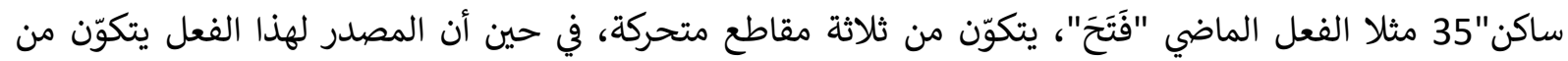

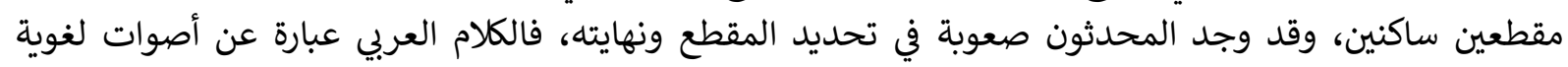

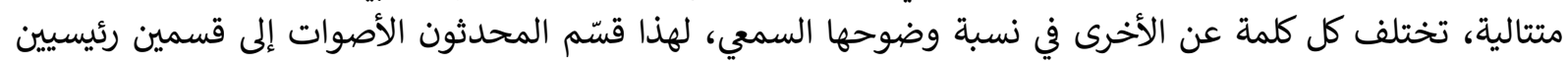

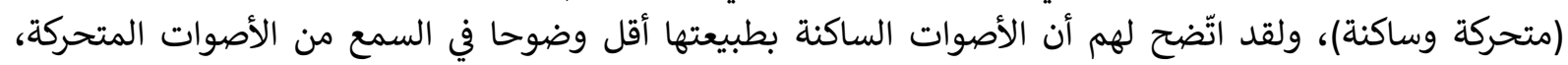

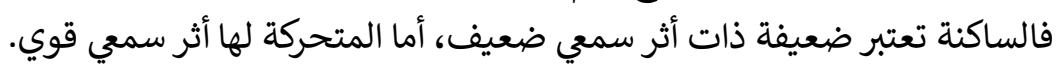

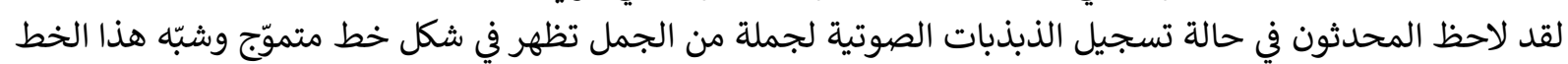

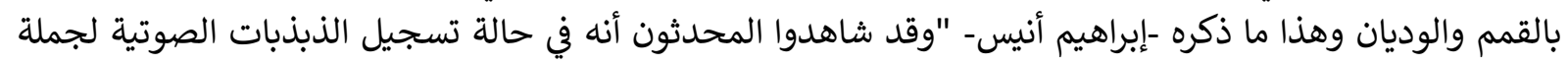

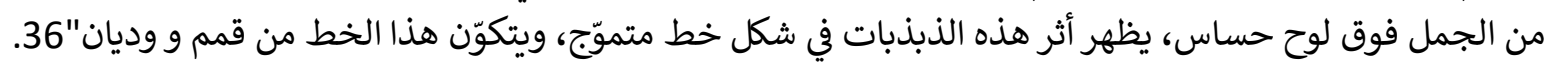

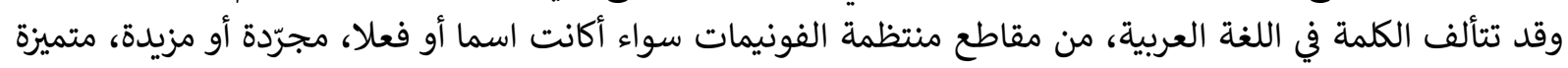

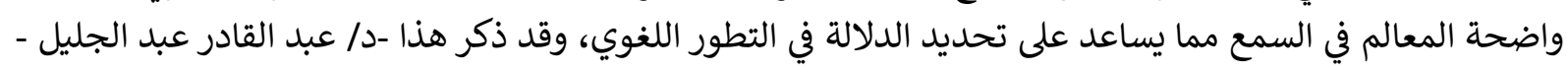

حيث تبين أن المقاطع في اللغة العربية تتوزع كالآني:37 المالى 1 1)- أحادية المقطع مثل: فَنْ 2) - ثنائية المقطع مثل: أُخْرُجْ 3)- ثلاثية المقطع مثل: سَاحِنْ 4) - رباعية المقطع مثل: مَلْرَرَّةُ

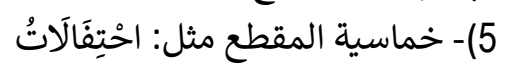
6)- سداسية المقطع مثل: اسْتِقَالَآتِهِمْ

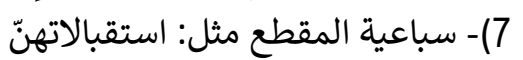

ويكاد يتّقق كل اللغويين(*) العرب المحدثين في تحديد البنية المقطعية الفصحى في خمسة أنسجة مقطعية -والتي تمّ ذوكرها سابقا-.

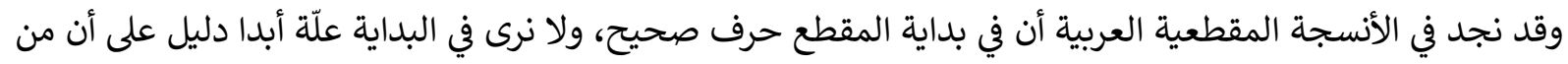

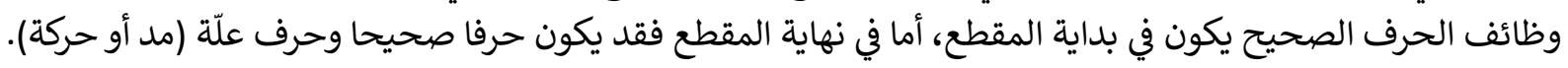

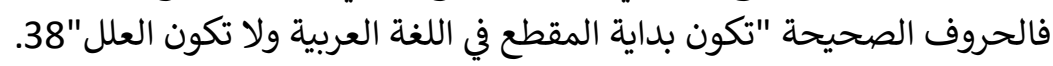

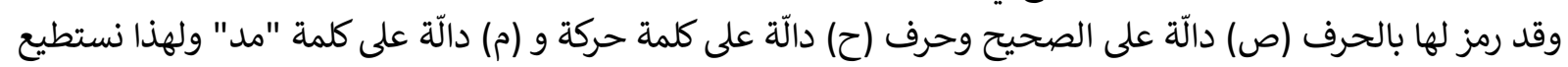

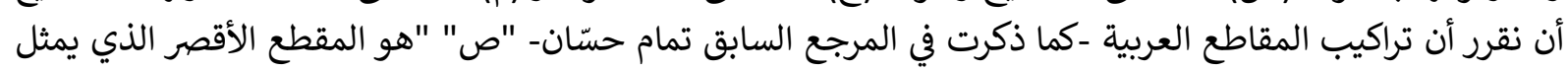

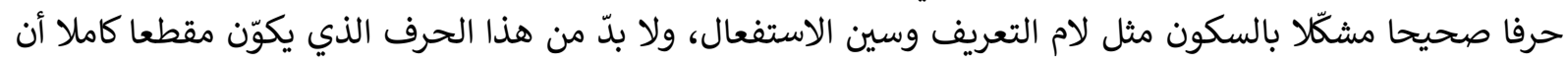

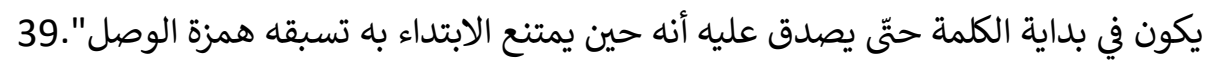

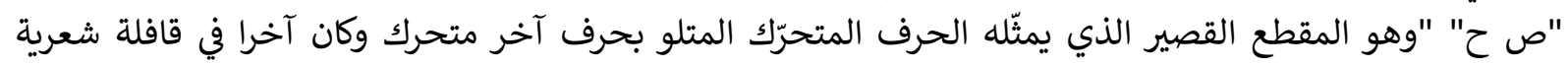

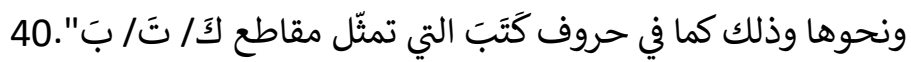

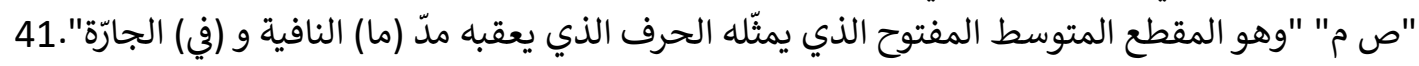

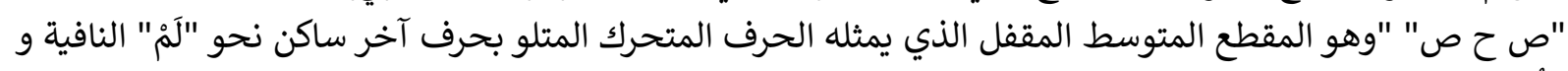

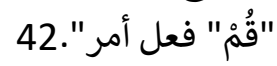


"ص ح ص ص" وهو المقطع الطويل بالتقاء الساكنين ويكثر في الوقف كما يأتي في غير الوقف أيضا كتصغير ساعة مثلا حيث تصير سويعة. وقد ينحصر نظام المصوّتات العربية الفصحى في ستّة حروف (فونيمات) "Phonèmes" كما ذكرت.

\author{
"a" الفتحة منفتحة \\ "i" الكسرة منفرجة منفتحة \\ "U" الضمة مضمومة أو مستديرة
}

وقد صنّفت هذه المصوّتات الثلاثة إما أن تكون طويلة أو قصيرة.

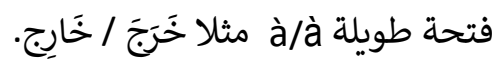

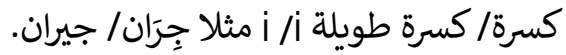

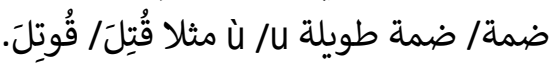

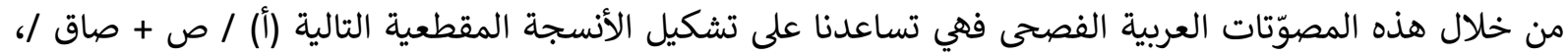

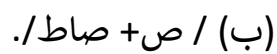

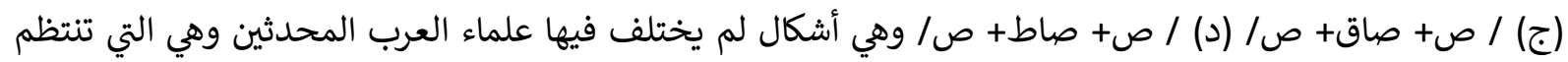

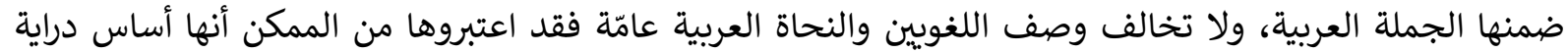

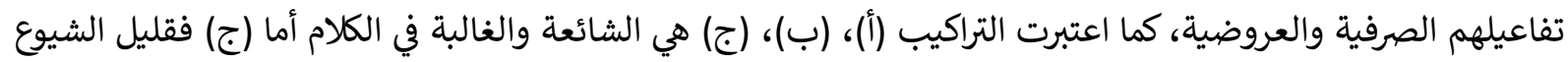

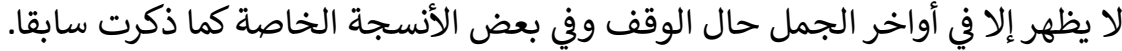

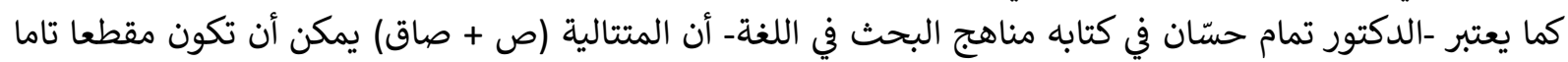

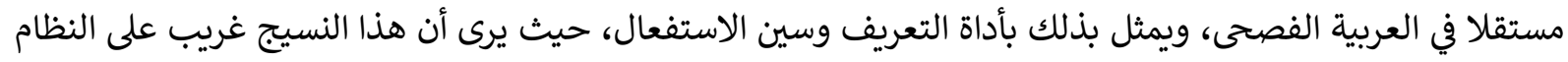
الصوتي، فأداة التعريف هي اللام الساكنة التي يقدمها.

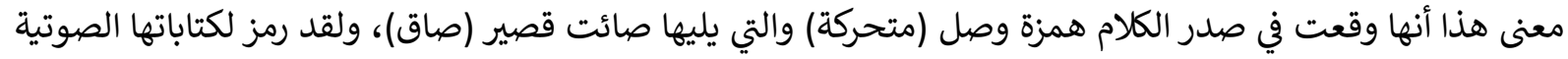

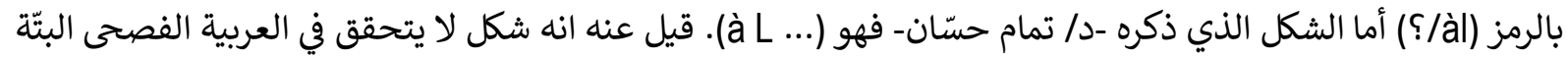

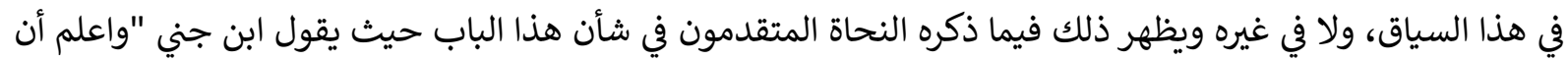

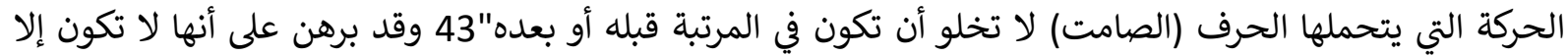

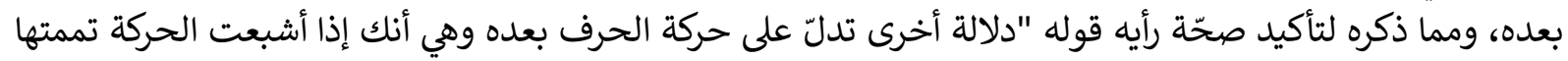

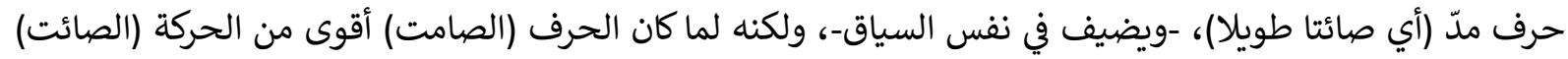

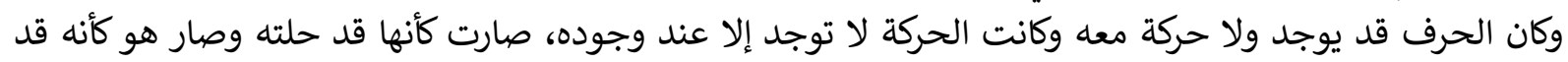

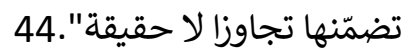

يمكن التوصل إلى استخلاص أمرين أساسيين:

1: أن الصائت لا يمكن أن يتحقق إلا إذا سبق بصامت كما سمّاه -إبراهيم أنيس- "حرف لين" وفي حين قد يوجد صامت

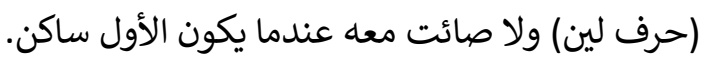

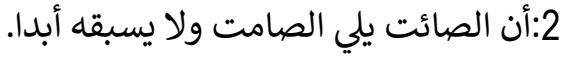
توجد صور من المقاطع في اللغة العربية فهناك:

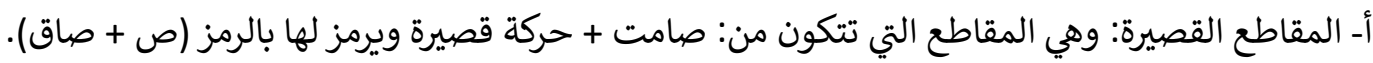
ب- المقاطع المتوسطة: وهي على نوعين:

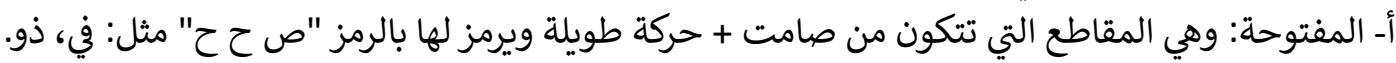

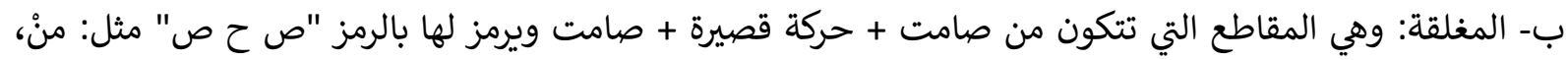
قدْن 


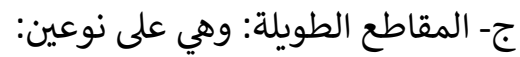

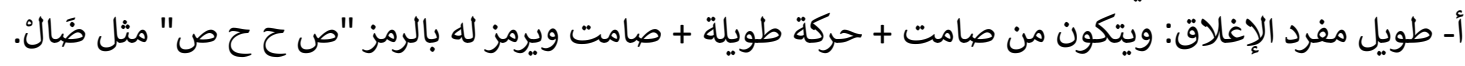

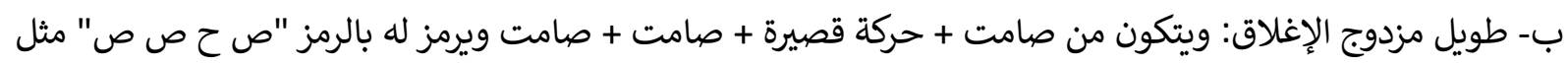

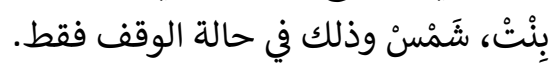

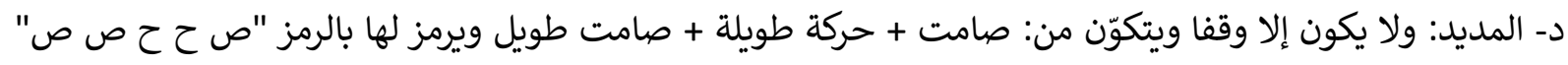

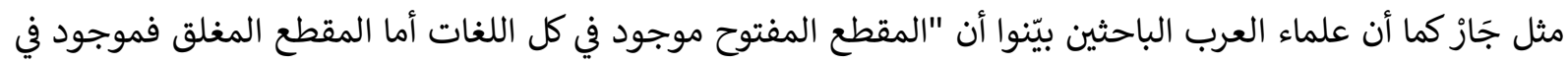

بعضها فقط"

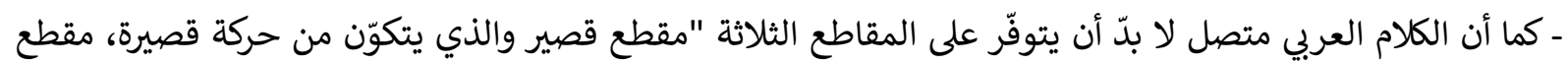

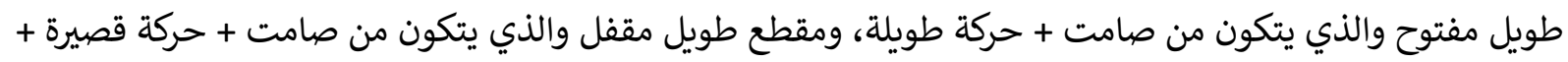

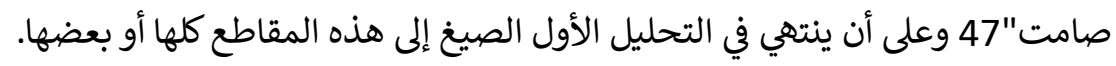

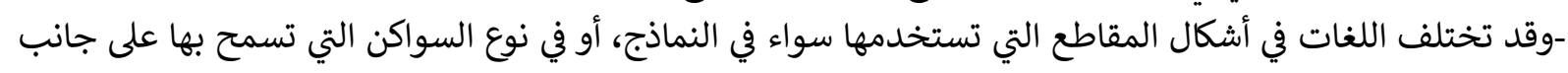
الصوت المقطي.48 فالمقطع في أبسط أشكاله "صورة يتكون من صامت وحركة (ص ح) فهي موجودة في الكثير من اللغات، ومنها العربية

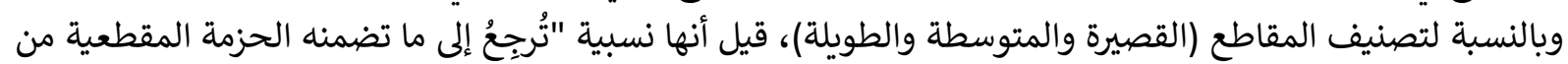

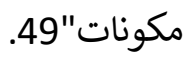

وحتى تتضح الصورة أكثر يمكن حصر هذه الأنسجة المقطعية في جدول توضيحي على الشكل الآتي:

\begin{tabular}{|c|c|c|c|}
\hline مثال & التسمية & شكله & \\
\hline سِ & مقطع قصير مفتوح & صامت+صائت قصير & النوع الأول \\
\hline بي & مقطع متوسط مفتوح & صامت+صائت طويل & 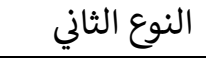 \\
\hline هَلْ & مقطع قصير مغلق & صامت+صائت قصير+صامت & 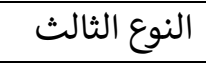 \\
\hline ديك & مقطع متوسط مفتوح & صامت+صائت طويل+صامت & النوع الرابع \\
\hline نهر & مقطع قصير مضاعف الإغلاق & صامت+صائت قصير+صامت+صامت & النوع الخامس \\
\hline
\end{tabular}

خامسا- خصائص المقطع العربي:

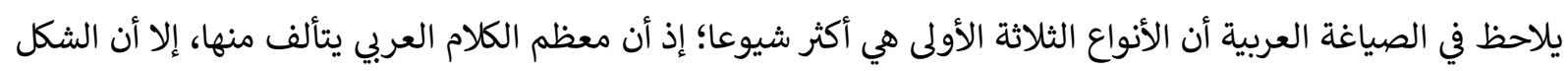

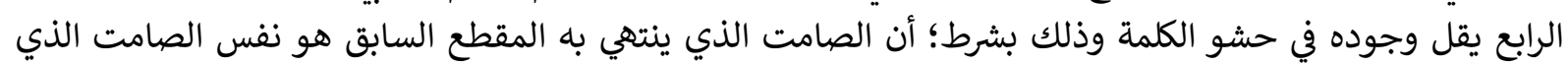

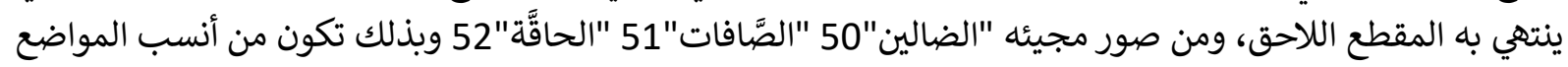
به هي نهاية الكلمات مثل "مهدمتان"

\section{وقد أسفرت الدراسات التي تناولت المقطع، على مجموعة من الخصائص التي يمكن إجمالها فيما يلي:}

1- أن جميع الأشكال المقطعية العربية تبتدئ بصامت ومن ثم فلا وجود في العربية لمقاطع تبتدئ بحركة

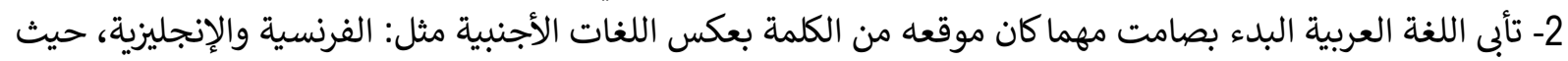

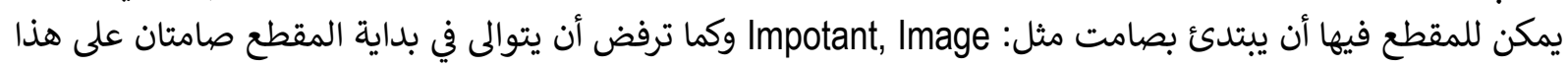

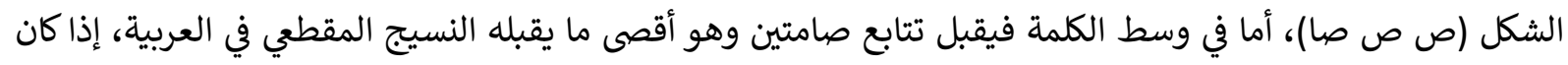

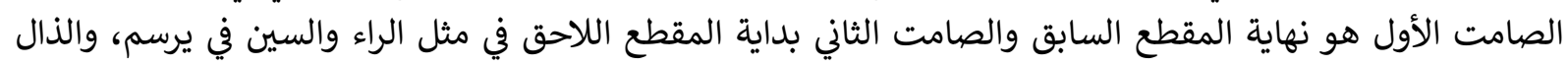

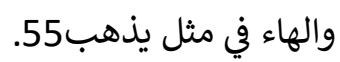
وقد أشار -عبد الصابور شاهين- إلى هذه النقطة بقوله: "لا يبدأ المقطع العربي بصامتين متواليين (ص+ص) ولإنائ ولا يتكون

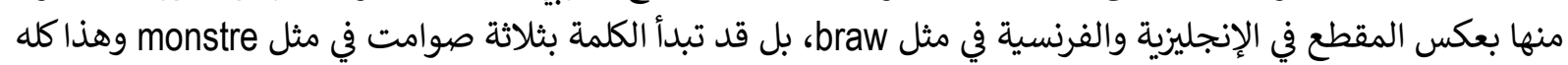

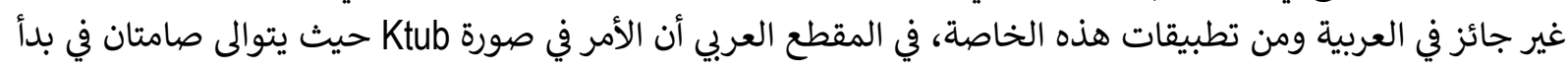

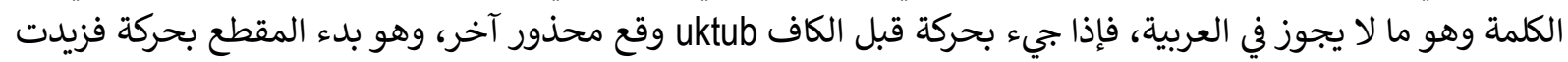

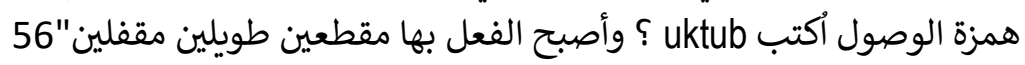


3-من خصائص التنظيم المقطي العربي، نجد أن أقل ما تتركب منه الكلمة العربية هو مقطع واحد، وأن أكثر ما تتكون

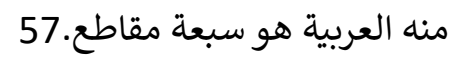
4- يتألف المقطع في اللغة العربية من وحدتين صوتيتين (أو أكثر) إحداهما حركة، فلا وجود لمقطع مؤلف من صوت واحد أو مقطع خال من حركة.585- يحتوي المقطع على صائت، ويعتبر عنصرا أساسيا ومركزيا في تكوين المقطع فتعدّ المقاطع في الجملة العربية بعدد

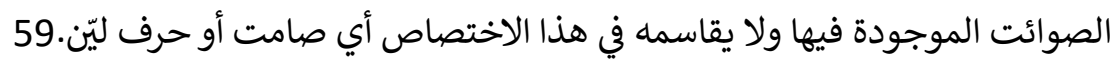

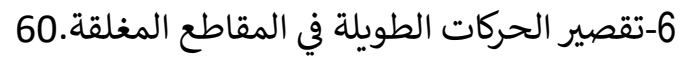

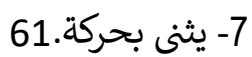

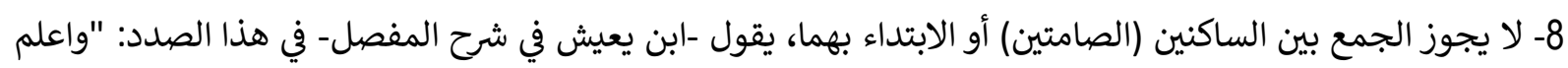

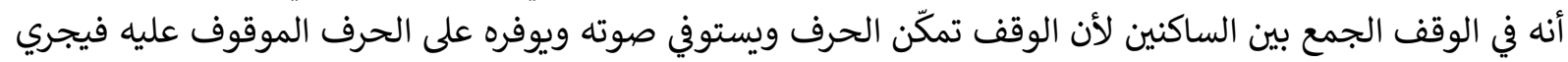

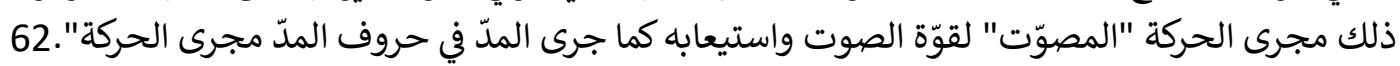
هذا بالنسبة إلى الخصائص والسمات التي تميّز المقطع العربي، اما فيما يخصّ تنظيم المقاطع داخل الكلمة فإن العربية: 1- لا تقبل لتوالي مقاطع قصيرة وكذلك مقاطع طويلة مفتوحة، وفي المقابل تميل غلى إغلاق المقاطع المفتوحة في غبر

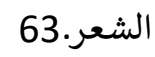
1 - ما ما لا تقبله اللغة العربية:

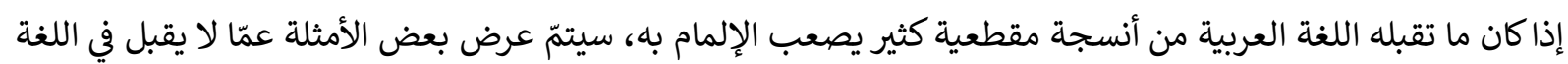
العربية، وإذا وجدت مثل هذه الكلمات فهي لا شكّ أعجمية دخيلة على آلى اللغة العبة العربية:

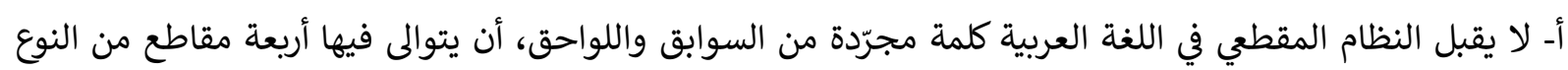

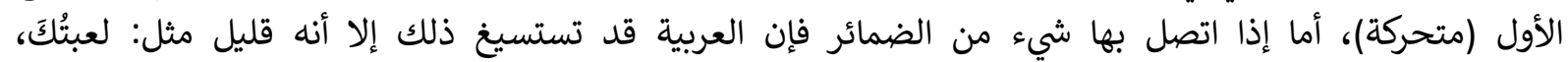
محفظتُكَ.64 ب- من الأشكال المقطعية المرفوضة في اللغة العربية كلمة احتوت في صدرها أو في حشوها مقطعا من النوع الخامس

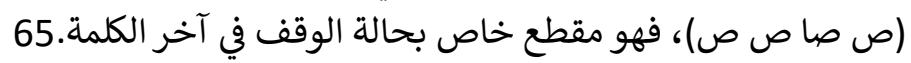

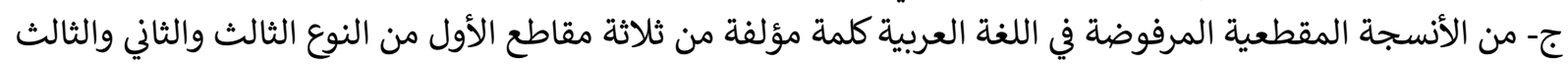
من النوع الثاني مثل: سِرْغَايَا.

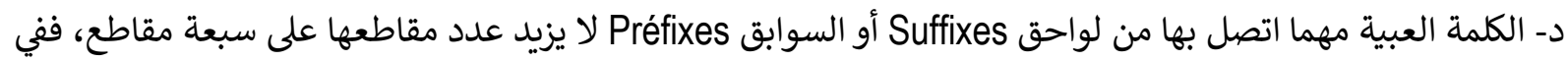

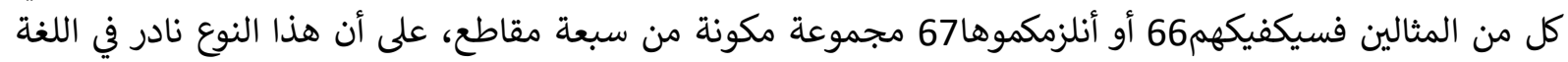

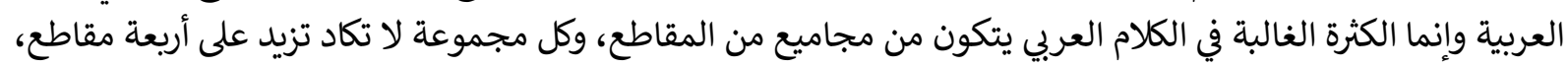

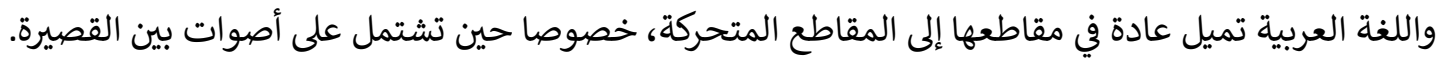

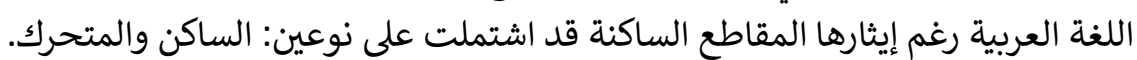

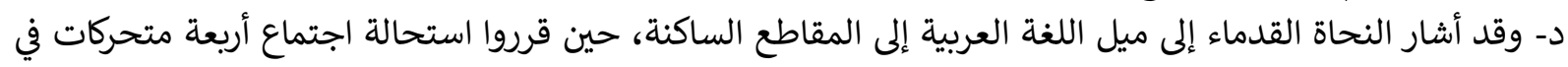

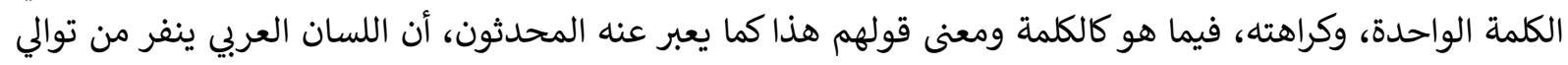

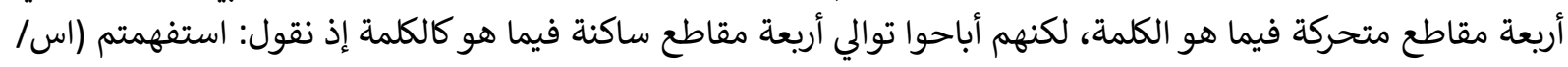

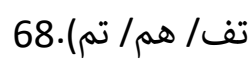

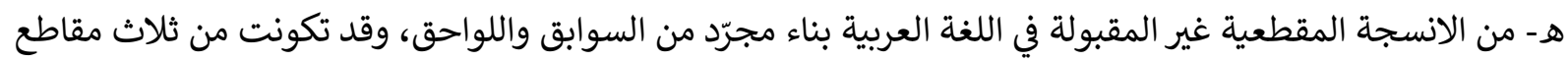

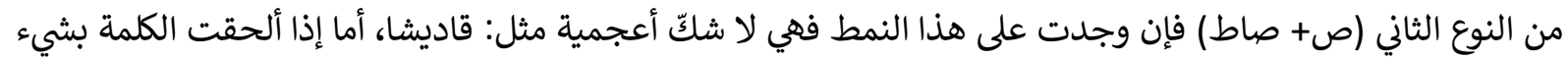

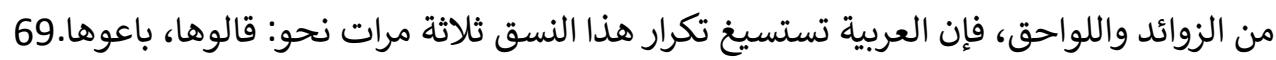

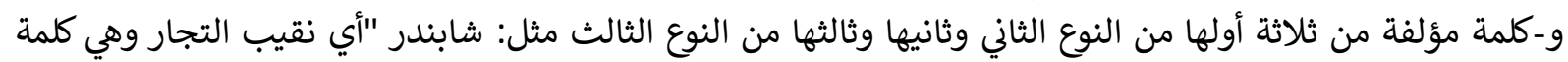
فارسيّة" 
س- كل كلمة اجتمع فيها مقطعان الأول من النوع الثاني والثاني من النوع الخامس، فهي لا شكّ أعجمية دخيلة على اللغة

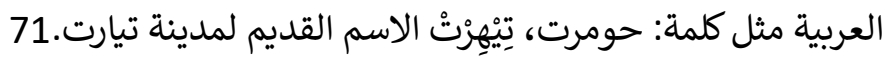

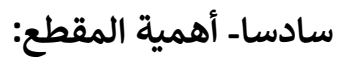

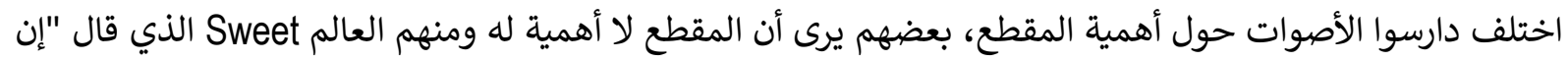

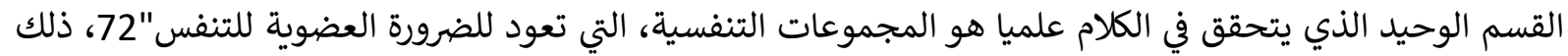

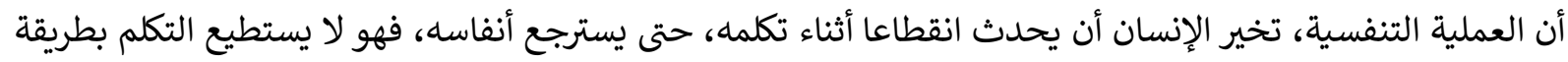

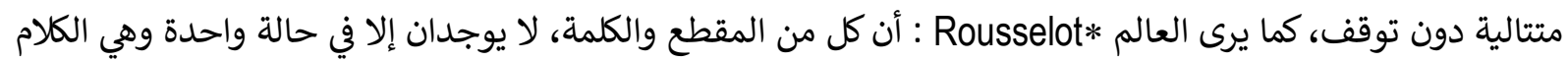

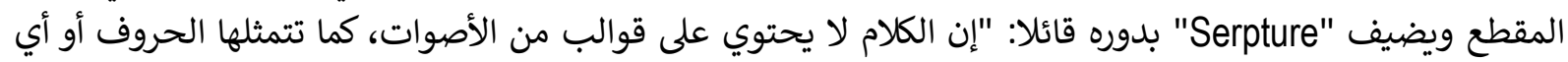

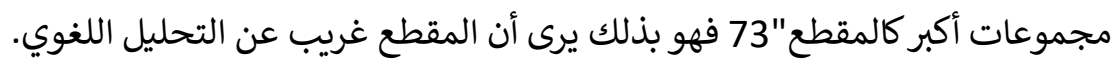

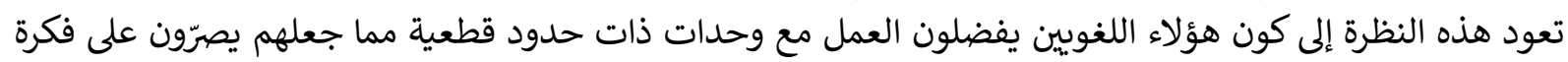

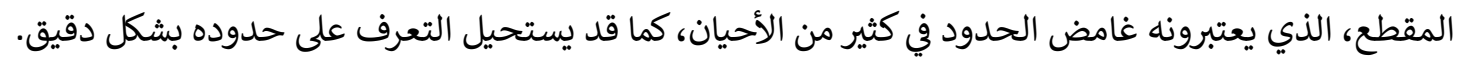

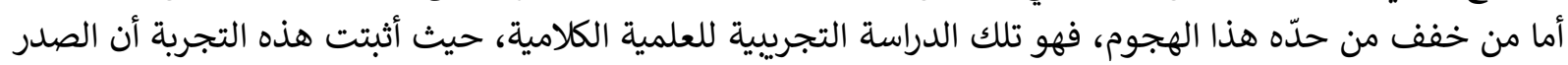

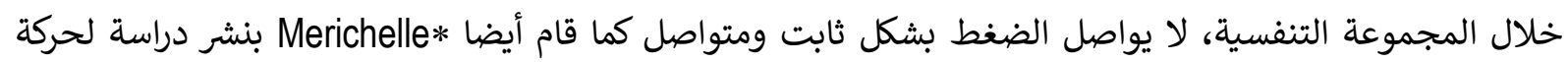

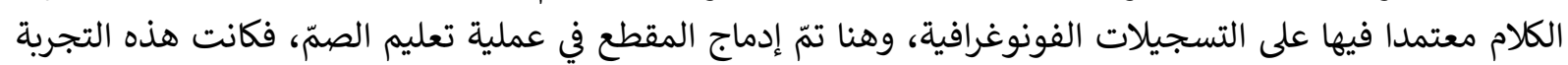

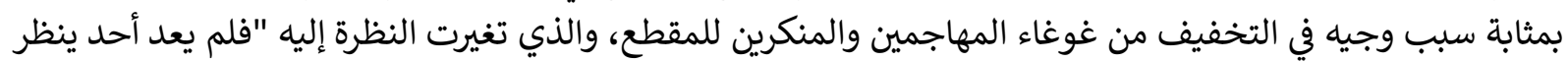

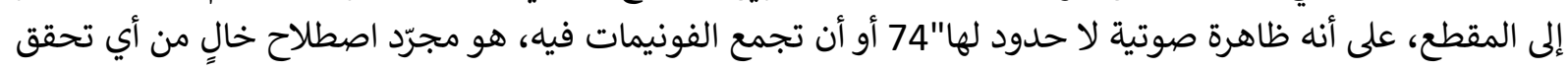

موضوعي.

\section{وتتمثل أهمية المقطع في نظر العديد من العلماء فيما يلي:}

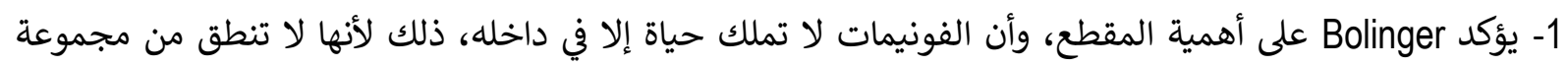

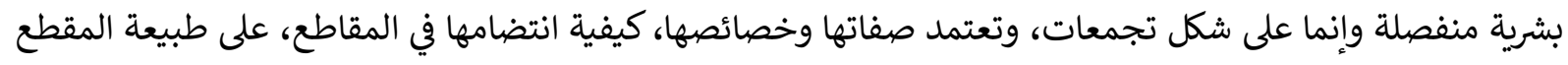
وتشكيلاته.75

2tetson مكألى أهمية الفونيمات التركيبية، المقطع النبر، التنغيم، ووحدتها الأساسية الفونيم، وأنها تشكل كلّا

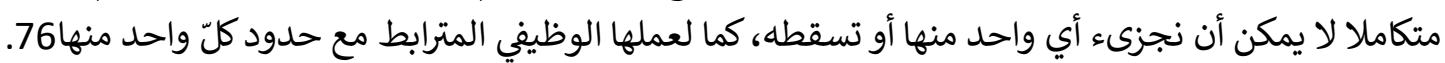

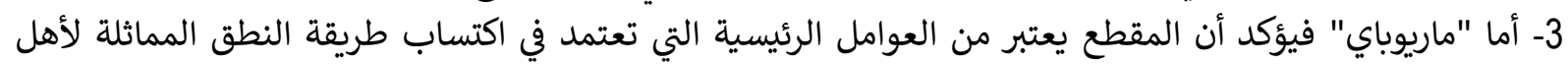

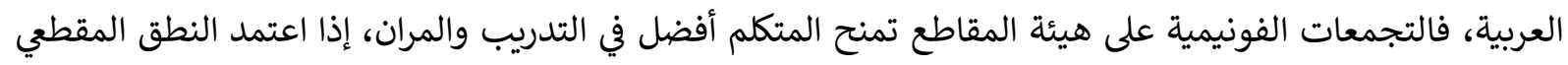

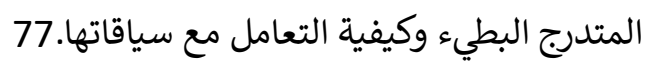
4- أما O'connor فئوكد المعلى أهمية دراسة المقطع، على أساس البعض من طرق الكتابة قد اعتمدت على الجانب المقطعي.78 5- للحركة أهمية كبيرة في بناء المقاطع في العربية، وفي غيرها من اللغات، ذلك أنه على أساس من موقع الحركة وكميتها،

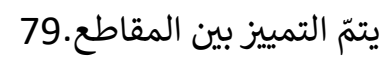

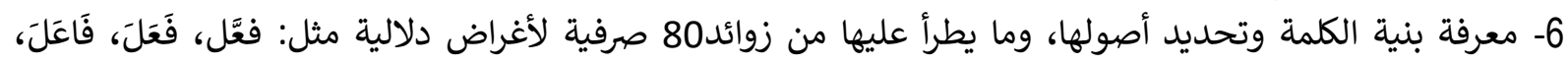
تَفَاعَلَ، استفعل...إلخ.

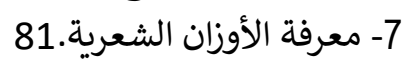
8- له دور في القراءات ولاسيما في علم التجويد.

سابعا- الخاتمة:

يستنتج من الدراسة أن للمقطع أهمية في الدراسة الصوتية، ويمكن إجمالها فيما يلي:

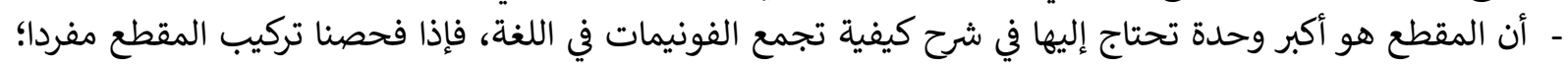
يمكننا أن نعتبر الوحدات الكبرى كتو كتابعات من المقاطع. 
ـ أن المقطع يشكل درجة في السلم الهرمي للوحدات الصوتية، الذي يشكل كل منها من أصغر وحدة تسبقه.

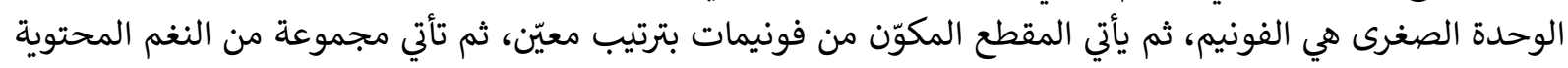

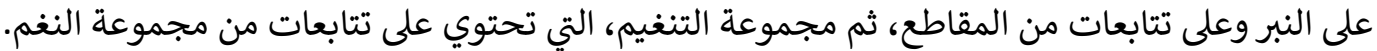

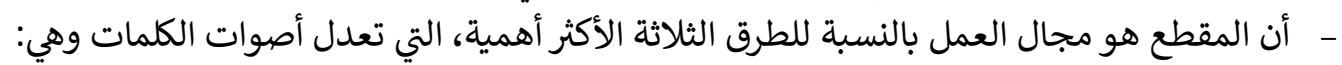
أ- النبر (سواء كان نبر الكلمة أو نبر الجملة الجملة).

ب- الإطالة ذات المعنى فتجعل كلمة awful -مثلا- أكثر تأكيد فنحن نمدّ المقطع الأول، المقطع المنبور.

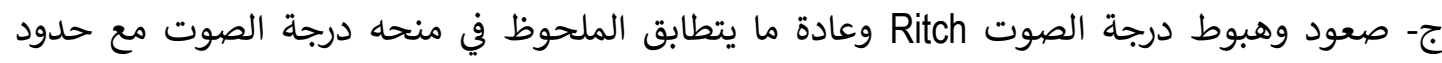

المقطع.

- - المقطع محل دراسة الفلاسفة والعلماء العرب القدامى بمنهج علمي يكاد يدنو منه الدرس اللساني الحديث.

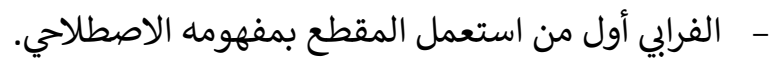
- القاضي عبد الجبار ما توصّل إليه جاء نتيجة المنهج الفيزيائي في دراسة الأصوات، واقتران ذلك بالبعد الزمني

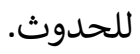

- - ابن سيناء عرّف المقطع بمعناه العلمي، من خلال تفصيله لمستويات الحدث الكلامي.

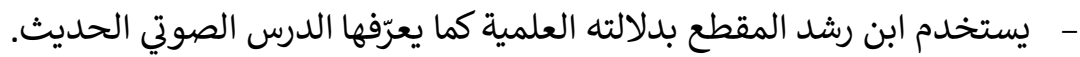

الهوامش والمصادر

*- Syllabe: Unité phonétique formée de consonnes et de voyelles qui se prononcent d'une seule émission de voix.

1- 2- عبد القادر عبد الجليل، الأصوات اللغوية، ص 215.

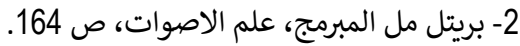

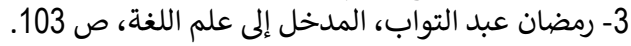

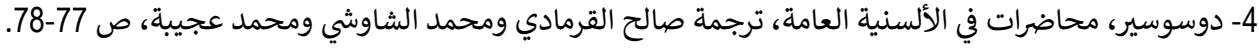

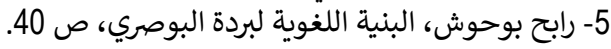

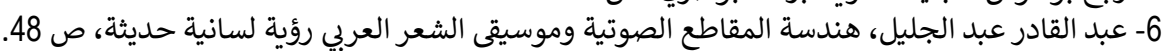

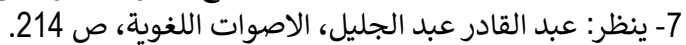

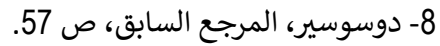

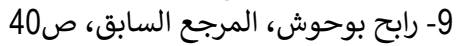

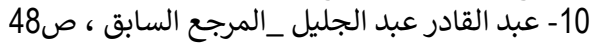

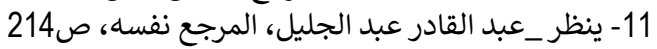

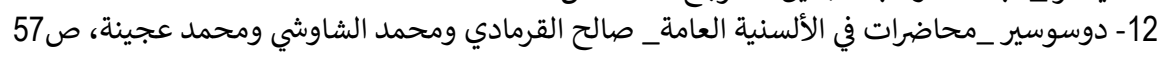

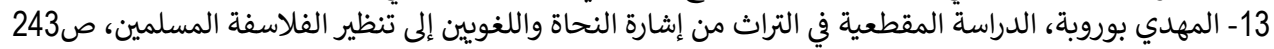

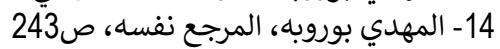

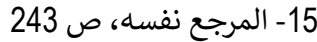

16 - المهدي بوروبة، الدراسة المقطعية في التراث من إشارات النحاة واللغويين إلى تنظير الفلاسفة المسلمين، ص243.

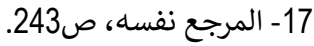
18- عبد السلام المسدي، التفكير اللساني في الحضارة العربية، ص284 و و 285 19- المهدي بوروبة، الدراسة المقطعية في الثراث من إشارات الثرات النحاة واللغويين إلى تنظير الفلاسفة المسلمين، ص284 ص284

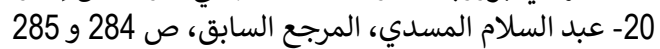

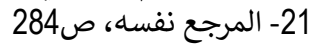

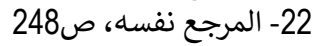

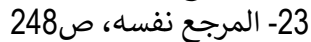

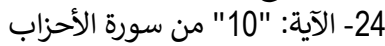
25- عبد السلام المسدي، التفكير اللساني في الحضارة العربية، ص263 الحس2

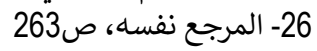
27- المهدي بوروبة، الدراسة المقطعية في التراث من إشارات النحاة واللغويين إلى تنظير الفلاسفة المسلمين، ص249

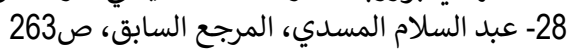

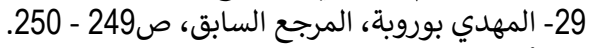

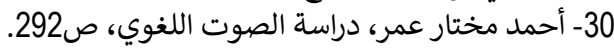


* - هذا التقسيم اعتمده كل من أحمد مختار عمر وحسام البهنساوي.

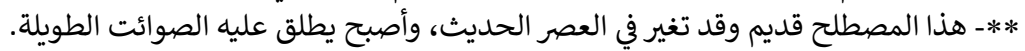

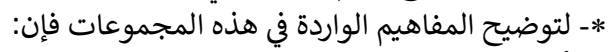

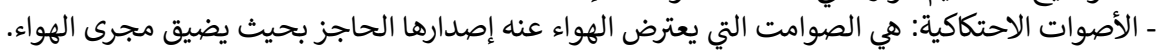

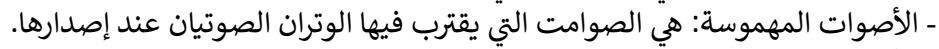

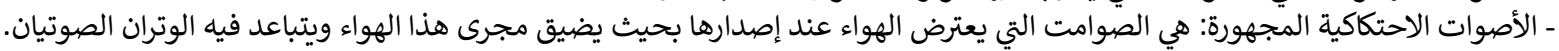

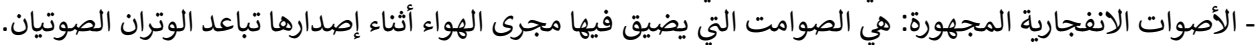

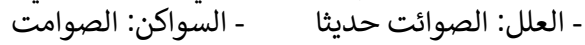

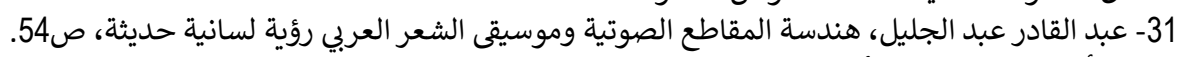

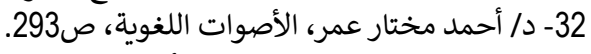
*- ضبط الرموز المستعملة في تلك الأنواع:

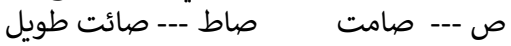
صا --- صائت صام --- صائت قصائت طويل

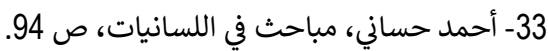

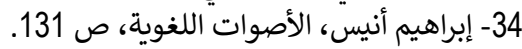

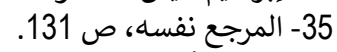

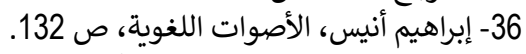

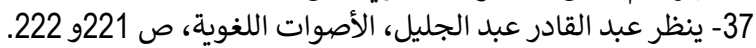

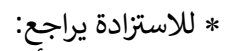

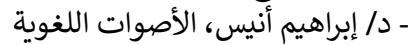
- د/ محمد الأنطاكي، المحيط الأيوات في الأصوات الغية العربية صرفها ونحوها

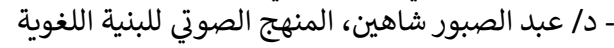

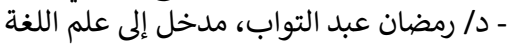

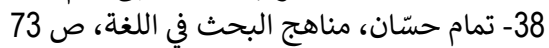

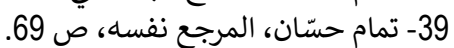
40- نفس المرجع، ص صن 69.

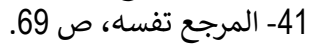

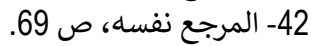

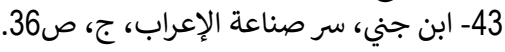

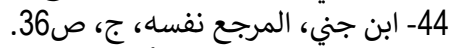

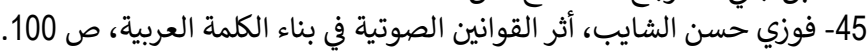

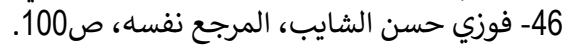

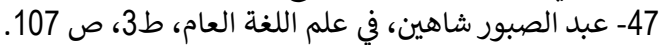

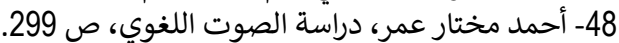

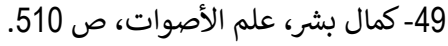

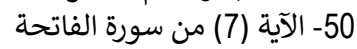
51- 51- الآية (1) من سآية (1) من سورة الصَّافات الفاتة 52- الآية (1) من الآية (1) من سورة الحاقة الصة منات

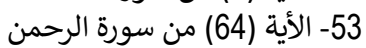

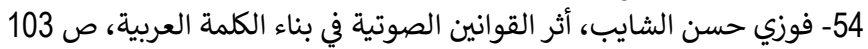

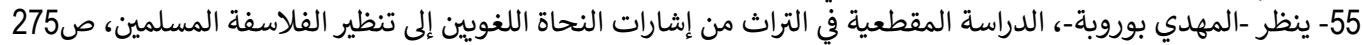

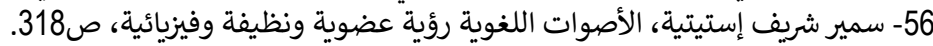

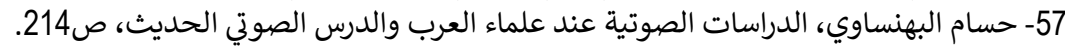

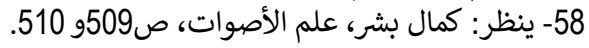

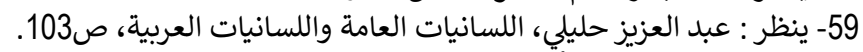

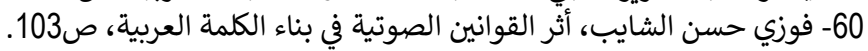

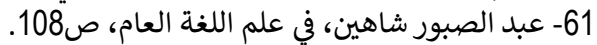

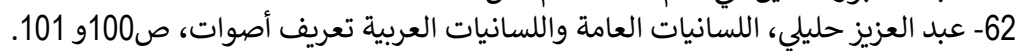

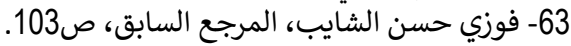

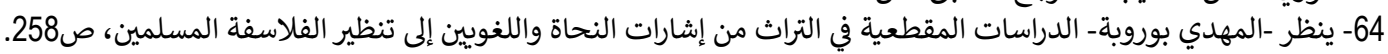

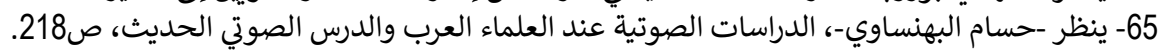

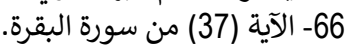
67- 68 الآية (28) من سورة هن سورد.

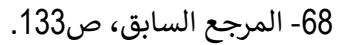

69- ينظر -المهدي بوريفة المرابة صورية-، الدراسة المقطعية في التراث من إشارات النحاة واللغويين إلى تنظير الفلاسفة المسلمين، ص258.

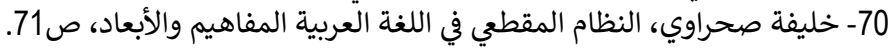




\section{1- 71- المرجع نفسه، ص71.}

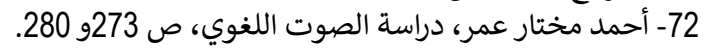

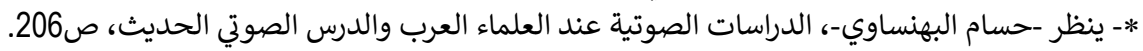

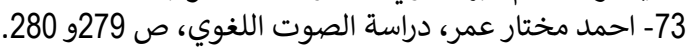
Merichell -*

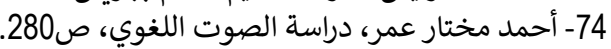

75- عبد القادر عبد الجليل، هندسة المقاطع الصوتية وموسيقى الشعر العربي رؤية لسانية حديثة، ص48. 76- المرجع نفسه، صبد صاديد.

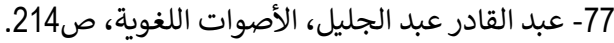

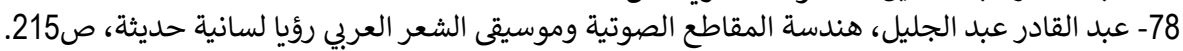

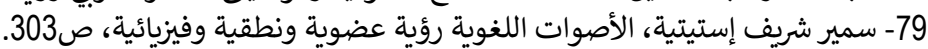

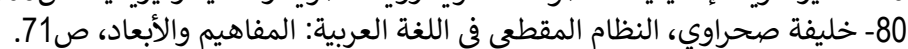

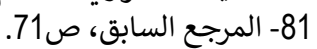

